Article

\title{
Separation of Hydrogen from Carbon Dioxide through Porous Ceramics
}

\author{
Taro Shimonosono, Hikari Imada, Hikaru Maeda and Yoshihiro Hirata *
}

Department of Chemistry, Biotechnology, and Chemical Engineering, Kagoshima University,

Kagoshima 890-0065, Japan; shimonosono@cen.kagoshima-u.ac.jp (T.S.); k2539294@kadai.jp (H.I.);

k0099848@kadai.jp (H.M.)

* Correspondence: hirata@cen.kagoshima-u.ac.jp; Tel.: +81-99-285-8325

Academic Editor: Tobias Fey

Received: 5 September 2016; Accepted: 10 November 2016; Published: 16 November 2016

\begin{abstract}
The gas permeability of $\alpha$-alumina, yttria-stabilized zirconia (YSZ), and silicon carbide porous ceramics toward $\mathrm{H}_{2}, \mathrm{CO}_{2}$, and $\mathrm{H}_{2}-\mathrm{CO}_{2}$ mixtures were investigated at room temperature. The permeation of $\mathrm{H}_{2}$ and $\mathrm{CO}_{2}$ single gases occurred above a critical pressure gradient, which was smaller for $\mathrm{H}_{2}$ gas than for $\mathrm{CO}_{2}$ gas. When the Knudsen number $(\lambda / r$ ratio, $\lambda$ : molecular mean free path, $r$ : pore radius) of a single gas was larger than unity, Knudsen flow became the dominant gas transportation process. The $\mathrm{H}_{2}$ fraction for the mixed gas of $(20 \%-80 \%) \mathrm{H}_{2}-(80 \%-20 \%) \mathrm{CO}_{2}$ through porous $\mathrm{Al}_{2} \mathrm{O}_{3}, \mathrm{YSZ}$, and $\mathrm{SiC}$ approached unity with decreasing pressure gradient. The high fraction of $\mathrm{H}_{2}$ gas was closely related to the difference in the critical pressure gradient values of $\mathrm{H}_{2}$ and $\mathrm{CO}_{2}$ single gas, the inlet mixed gas composition, and the gas flow mechanism of the mixed gas. Moisture in the atmosphere adsorbed easily on the porous ceramics and affected the critical pressure gradient, leading to the increased selectivity of $\mathrm{H}_{2}$ gas.
\end{abstract}

Keywords: gas separation; hydrogen; carbon dioxide; porous ceramics

\section{Introduction}

Currently, $90 \%$ of the hydrogen gas produced in the world is generated by a steam reforming process of naphtha (Equation (1)) followed by a water-gas shift reaction (Equation (2)):

$$
\begin{gathered}
\mathrm{C}_{\mathrm{m}} \mathrm{H}_{\mathrm{n}}+\mathrm{mH}_{2} \mathrm{O} \rightarrow(\mathrm{m}+\mathrm{n} / 2) \mathrm{H}_{2}+\mathrm{mCO} \\
\mathrm{mCO}+\mathrm{mH}_{2} \mathrm{O} \rightarrow \mathrm{mH}_{2}+\mathrm{mCO}_{2} .
\end{gathered}
$$

The reformed gas contains hydrogen and carbon dioxide. The byproduct, carbon dioxide, is usually removed by a pressure swing adsorption method or a cryogenic distillation method at a low temperature. However, the separation of hydrogen from carbon dioxide at high temperatures of $200-400{ }^{\circ} \mathrm{C}$ (i.e., the reaction temperature of Equation (2)) using a membrane separator is desirable from the point of view of reducing the energy consumption and costs associated with hydrogen refinement.

Polyimide membranes are well-known commercialized membranes for separating hydrogen gas at operating temperatures less than $200{ }^{\circ} \mathrm{C}$ [1,2]. In polymer membranes used to separate gases, the gas molecules are transported through the spaces of the polymer chain network. Hydrogen molecules, which are small, permeate through the polymer membrane more easily than other gases. For example, when a mixture of $10 \mathrm{vol} \% \mathrm{H}_{2}$ and $90 \mathrm{vol} \% \mathrm{CO}_{2}$ was fed at $0.4-0.6 \mathrm{MPa}$ to a polyimide membrane with a thickness of approximately $50 \mu \mathrm{m}$ [1], the $\mathrm{H}_{2}$ selectivity (i.e., the ratio between the permeability coefficients of $\mathrm{H}_{2}$ and $\mathrm{CO}_{2}$ ) was 2.7, whereas the $\mathrm{H}_{2}$ permeability coefficient was approximately $3 \times 10^{-15} \mathrm{~mol} \cdot \mathrm{m} /\left(\mathrm{m}^{2} \cdot \mathrm{s} \cdot \mathrm{Pa}\right)[1]$. 
To enhance the $\mathrm{H}_{2}$ selectivity of polymer membranes, researchers have added metal [3] and have modified the surface of polymers with amine groups [4] to increase the membranes' affinity toward $\mathrm{CO}_{2}$ gas and prevent the diffusion of $\mathrm{CO}_{2}$ molecules. At higher temperatures, a palladium metal membrane [5] or an amorphous silica membrane [6] is used, in which hydrogen atoms diffuse through atomic-sized spaces. In the Pd membrane, the dissociative dissolution of $\mathrm{H}_{2}$ molecules occurs selectively and is followed by the diffusion of $\mathrm{H}$ atoms. Studies of $\mathrm{Pd}$ membranes have focused on the fabrication of a thin Pd film without pinholes to increase the flux of permeated $\mathrm{H}_{2}$ gas and the $\mathrm{H}_{2}$ selectivity. Preventing delamination of the Pd membrane from its supporting material is important. Thus, researchers have developed Pd alloy membranes to suppress the phase transformation due to hydrogenation of Pd metal, which is accompanied by volume expansion [5,7]. The use of a metal support to reduce the mismatch between the thermal expansion coefficients of a Pd membrane and its supporting material has also been investigated [8]. In membranes with micropores $(<2 \mathrm{~nm})$, such as amorphous silica, smaller gas molecules move more easily through the pores. The challenge with such membranes is to prevent the collapse of the micropores at high temperatures $\left(>450{ }^{\circ} \mathrm{C}\right)$; polysilazane-derived silicon carbonitrides have been reported to satisfy this requirement $[9,10]$, and a further improvement in thermal stability of microporous structures by the addition of Ni has also been reported [11]. In these membranes, the selectivity of hydrogen gas is sufficiently high; however, a high flux of hydrogen gas is achieved only under a high pressure of a supplied gas.

A membrane with 10-nm-diameter pores is expected to exhibit a hydrogen gas flux greater than that in the aforementioned membranes. The flux $(J)$ of gas through a porous material is expressed theoretically by the Knudsen or Poiseuille equation (Equation (3)):

$$
J=\alpha \frac{\Delta P}{L}
$$

where $\alpha$ is the permeability coefficient of gas $\left(\alpha=2 \varepsilon r \bar{c} / 3 R T\right.$ for the Knudsen equation, $\alpha=\varepsilon r^{2} \bar{P} / 8 R T \eta$ for the Poiseuille equation); $\Delta P / L$ is the pressure gradient between the inlet and outlet gases; $\varepsilon$ and $r$ are the open porosity and pore radius of a porous membrane, respectively; $\bar{P}$ is the average pressure between the inlet and outlet gases; $\eta$ is the viscosity of the gas; $\bar{c}$ is the average velocity of gas molecules ( $\bar{c}=\sqrt{8 R T / \pi M}$, where $M$ is the molecular weight of the gas molecules); $R$ is the gas constant; and $T$ is the absolute temperature. The fraction $(F)$ of hydrogen gas of the outlet gas for $50 \mathrm{vol} \% \mathrm{H}_{2}-50 \mathrm{vol} \%$ $\mathrm{CO}_{2}$ mixed gas is calculated by Equations (4) and (5) for Knudsen and Poiseuille flow, respectively:

$$
\begin{gathered}
F_{\mathrm{K}}\left(\mathrm{H}_{2}\right)=\frac{J\left(\mathrm{H}_{2}\right)}{J\left(\mathrm{H}_{2}\right)+J\left(\mathrm{CO}_{2}\right)}=\frac{\bar{c}\left(\mathrm{H}_{2}\right)}{\overline{\bar{c}}\left(\mathrm{H}_{2}\right)+\bar{c}\left(\mathrm{CO}_{2}\right)}=\frac{\sqrt{M\left(\mathrm{CO}_{2}\right)}}{\sqrt{M\left(\mathrm{CO}_{2}\right)}+\sqrt{M\left(\mathrm{H}_{2}\right)}} \\
F_{\mathrm{P}}\left(\mathrm{H}_{2}\right)=\frac{J\left(\mathrm{H}_{2}\right)}{J\left(\mathrm{H}_{2}\right)+J\left(\mathrm{CO}_{2}\right)}=\frac{\eta\left(\mathrm{CO}_{2}\right)}{\eta\left(\mathrm{CO}_{2}\right)+\eta\left(\mathrm{H}_{2}\right)} .
\end{gathered}
$$

The $F$ value based on viscosities [12] of $8.73 \mu \mathrm{Pa} \cdot \mathrm{s}$ for $\mathrm{H}_{2}$ gas and $14.53 \mu \mathrm{Pa} \cdot \mathrm{s}$ for $\mathrm{CO}_{2}$ gas at $17^{\circ} \mathrm{C}$ is 0.824 in Equation (4) and 0.611 in Equation (5). Note that the $F$ value is related to the generally defined selectivity (i.e., the ratio between the permeability coefficients of the major and minor permeant gases) by Equation (6):

$$
f\left(\mathrm{H}_{2}\right)=\frac{\alpha\left(\mathrm{H}_{2}\right)}{\alpha\left(\mathrm{CO}_{2}\right)}=\frac{F\left(\mathrm{H}_{2}\right)}{1-F\left(\mathrm{H}_{2}\right)} .
$$

The ratio of molecular mean free path to the pore size (i.e., the Knudsen number) determines the mechanism of gas flow. Figure 1 shows the molecular mean free paths $(\lambda)$ of $\mathrm{H}_{2}$ and $\mathrm{CO}_{2}$ gases calculated by Equation (7) at $290 \mathrm{~K}$ [13].

$$
\lambda=\frac{\eta}{0.499 P \sqrt{8 M /(\pi R T)}}
$$


The $\lambda$ value increases with decreasing gas pressure and is larger for $\mathrm{H}_{2}$ gas than for $\mathrm{CO}_{2}$ gas. When the $\lambda / r$ (pore radius) ratio is less than unity, Poiseuille flow becomes dominant. For instance, $\mathrm{H}_{2}$ and $\mathrm{CO}_{2}$ gases exhibit Knudsen and Poiseuille flow, respectively, in a pore with an 80-nm radius (Figure 1), thereby influencing the flux of transported gas.

One approach to enhancing the selectivity of a gas permeated through porous ceramics is to modify the surfaces of ceramic particles by an agent that interacts with a gas and suppresses the permeation of the other mixed gas (e.g., $\mathrm{AlOOH}$ [14] and silane coupling agents [15] interact with $\mathrm{CO}_{2}$ gas). In this work, we used another approach to enhance the selectivity of a gas permeated through porous ceramics. In our previous study [16,17], the $J-\Delta P / L$ relation for $\mathrm{CO}_{2}$ gas was observed at pressures greater than a critical pressure gradient $\left(\Delta P_{c} / L\right)$, as shown in Figure 2. However, the critical pressure gradient of $\mathrm{H}_{2}$ gas was closer to $0 \mathrm{MPa} / \mathrm{m}$. This difference in critical pressure gradients can be exploited to separate $\mathrm{H}_{2}$ gas from $\mathrm{CO}_{2}$ gas in the $\Delta P / L$ range below the $\Delta P_{c} / L$ for $\mathrm{CO}_{2}$ gas. A large difference in the $\Delta P_{c} / L$ values for two gases also favors an increase in the flux of a selected gas at a relatively low pressure. In this study, the selectivity of the $\mathrm{H}_{2}-\mathrm{CO}_{2}$ mixed gas was investigated at room temperature using porous ceramics of $\alpha$-alumina, yttria-stabilized zirconia (YSZ), and silicon carbide.

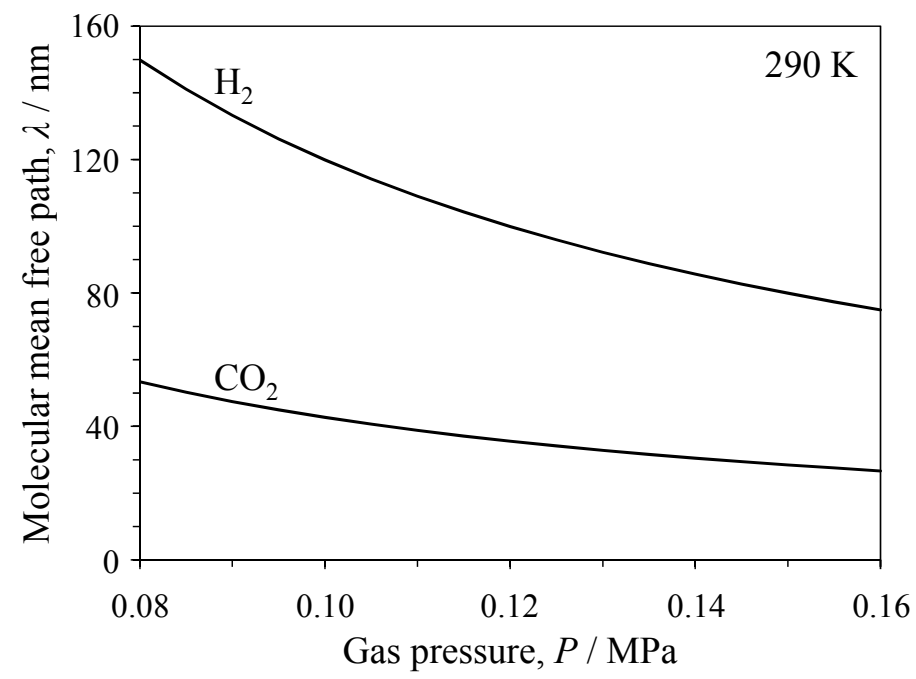

Figure 1. Molecular mean free paths of $\mathrm{H}_{2}$ and $\mathrm{CO}_{2}$ molecules as a function of gas pressure.

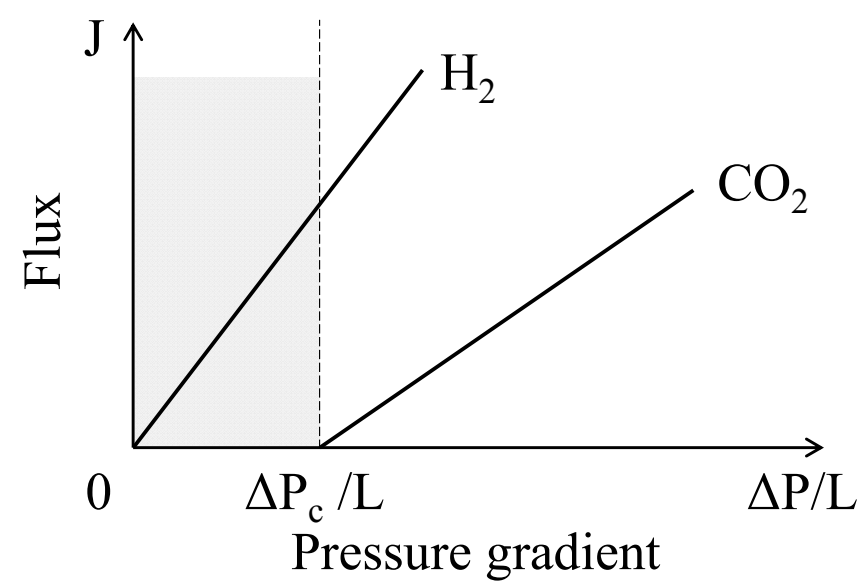

Figure 2. Schematic showing the flux-pressure gradient relation of $\mathrm{H}_{2}$ and $\mathrm{CO}_{2}$ gases through porous ceramics. A critical pressure gradient $\left(\Delta P_{\mathrm{c}} / L\right)$ is observed for $\mathrm{CO}_{2}$ gas. 


\section{Experimental}

\subsection{Fabrication of Porous Ceramics}

The employed powders were $\alpha$-alumina (AKP50, specific surface area $(S) 10.5 \mathrm{~m}^{2} / \mathrm{g}$, equivalent diameter (D) $143 \mathrm{~nm}$, isoelectric point (iep) $\mathrm{pH}$ 8.5, Sumitomo Chemical Co., Ltd., Tokyo, Japan), YSZ (TZ-8Y, $92 \mathrm{~mol} \% \mathrm{ZrO}_{2}-8 \mathrm{~mol} \% \mathrm{Y}_{2} \mathrm{O}_{3}, S=14.9 \mathrm{~m}^{2} / \mathrm{g}, \mathrm{D}=68.3 \mathrm{~nm}$, iep $=\mathrm{pH} 7.8$, Tosoh Co., Tokyo, Japan) and $\mathrm{SiC}$ (impurity, mass\%: $\mathrm{SiO}_{2}$ 0.66, C 0.37, $\mathrm{Al} 0.004$ and $\mathrm{Fe} 0.013, S=13.4 \mathrm{~m}^{2} / \mathrm{g}$, $D=139 \mathrm{~nm}$, iep $=\mathrm{pH}$ 2.5, Yakushima Electric Industry Co., Ltd., Tokyo, Japan). Each powder of $\mathrm{Al}_{2} \mathrm{O}_{3}$ and YSZ was dispersed at a solid content of $30 \mathrm{vol} \%$ in double-distilled water adjusted with an $\mathrm{HCl}$ solution at $\mathrm{pH} 3$ where the particles were charged positively to increase the electrostatic repulsive energy among the particles. After stirring for $24 \mathrm{~h}$, the suspensions were consolidated by pressure filtration at pressures as high as $19 \mathrm{MPa}$ and were dried at $100{ }^{\circ} \mathrm{C}$ in air for $24 \mathrm{~h}$. The obtained $\mathrm{Al}_{2} \mathrm{O}_{3}$ and YSZ compacts were sintered at 800 and $1100{ }^{\circ} \mathrm{C}$, respectively, in air for $1 \mathrm{~h}$. In the fabrication of porous $\mathrm{SiC}$ compacts, the sintering additives of $\alpha$-alumina (AKP50) and yttria (purity $>99.9$ mass $\%$, $S=15.0 \mathrm{~m}^{2} / \mathrm{g}, D=79.5 \mathrm{~nm}$, iep $=\mathrm{pH} 7.5$, Shin-Etsu Chemical Co., Ltd., Tokyo, Japan) were mixed in a mass ratio of $\mathrm{SiC}: \mathrm{Al}_{2} \mathrm{O}_{3}: \mathrm{Y}_{2} \mathrm{O}_{3}=1: 0.02: 0.02$. The aqueous suspension was prepared at a solid content of $30 \mathrm{vol} \%$ at $\mathrm{pH} 5$, where the positively charged sintering additives were attracted to the negatively charged $\mathrm{SiC}$ particles to form heterocoagulated particle clusters. After stirring for $24 \mathrm{~h}$, the suspension was consolidated over a gypsum board. The obtained compacts were hot-pressed at 1400,1500 , or $1700{ }^{\circ} \mathrm{C}$ under a pressure of $39 \mathrm{MPa}$ in an argon atmosphere for $2 \mathrm{~h}$. The densities of fabricated compacts were measured by the Archimedes method using double-distilled water. The microstructures were observed by field-emission scanning electron microscopy (FE-SEM, S- $4100 \mathrm{H}$, Hitachi High-Technologies Co., Tokyo, Japan); the pore size distributions were analyzed via an intercept method [18]. The two-dimensional pore size determined by the intercept method was converted into a three-dimensional pore size by multiplying by a factor of 1.56, where the pores were assumed to be spherical [19]. The pore size distributions were also measured by mercury porosimetry at the Saga Ceramics Research Laboratory in Japan (Arita-cho, Nishimatsuura-gun, Saga 844-0024, Saga, Japan).

\subsection{Gas Permeation in Porous Ceramics}

The $\mathrm{Al}_{2} \mathrm{O}_{3}$ and YSZ samples were formed into disk shapes $20 \mathrm{~mm}$ in diameter and $3 \mathrm{~mm}$ in thickness. The diameter and thickness of the $\mathrm{SiC}$ disk sample were 10 and $3 \mathrm{~mm}$, respectively. The side of each sample was sealed with phenolic resin. Before the gas separation experiments, each sample was dried at $100{ }^{\circ} \mathrm{C}$ for $24 \mathrm{~h}$. The amount of moisture adsorbed on the dried sample was measured by a thermogravimetric/differential thermal analyzer (TG/DTA, Thermoplus, Rigaku, Tokyo, Japan). When the sample dried at $100{ }^{\circ} \mathrm{C}$ for $24 \mathrm{~h}$ was heated to $600{ }^{\circ} \mathrm{C}$ at the heating rate of $10^{\circ} \mathrm{C} / \mathrm{min}$, the weight losses of $\mathrm{Al}_{2} \mathrm{O}_{3}$ and $\mathrm{YSZ}$ porous ceramics were about $0.25 \%$ and $0.20 \%$, respectively. In the $\mathrm{Al}_{2} \mathrm{O}_{3}$ and YSZ samples dried at $300{ }^{\circ} \mathrm{C}$ for $24 \mathrm{~h}$, the weight losses were about $0.25 \%$ and $0.10 \%$, respectively. These results indicate that moisture in the atmosphere adsorbs easily on the present porous ceramics during the gas separation experiment. The sample to be measured was placed in a stainless steel holder, as shown in Figure 3. Rubber rings were placed in front of and behind the stainless spacers and were compressed by the stainless holder to avoid gas leakage. $\mathrm{H}_{2}\left(>99.999 \%\right.$ purity), $\mathrm{CO}_{2}(>99.99 \%$ purity) and mixed gases with 20,50, and $80 \mathrm{vol} \% \mathrm{H}_{2}$ were supplied at pressures as high as $0.199 \mathrm{MPa}$ at room temperature. The pressure of the permeated gas was approximately constant at $0.101 \mathrm{MPa}$. The gas pressure was monitored using a pressure gauge (MJE-PPX No. 0003-81V, CKD Co., Ltd., Aichi, Japan). The flux of permeated gas was measured using a flow meter (Soapfilm Flow Meter, 3001-11002, GL Science Inc., Tokyo, Japan). The compositions of inlet and outlet gases were measured using a gas chromatograph equipped with an active carbon column and a thermal conductivity detector (GT7100T, J-ScienceLab Co., Ltd., Tokyo, Japan). The temperatures of the column and detector were 70 and $100{ }^{\circ} \mathrm{C}$, respectively. The electric current supplied to the detector was $60 \mathrm{~mA}$, and the carrier gas was argon. 


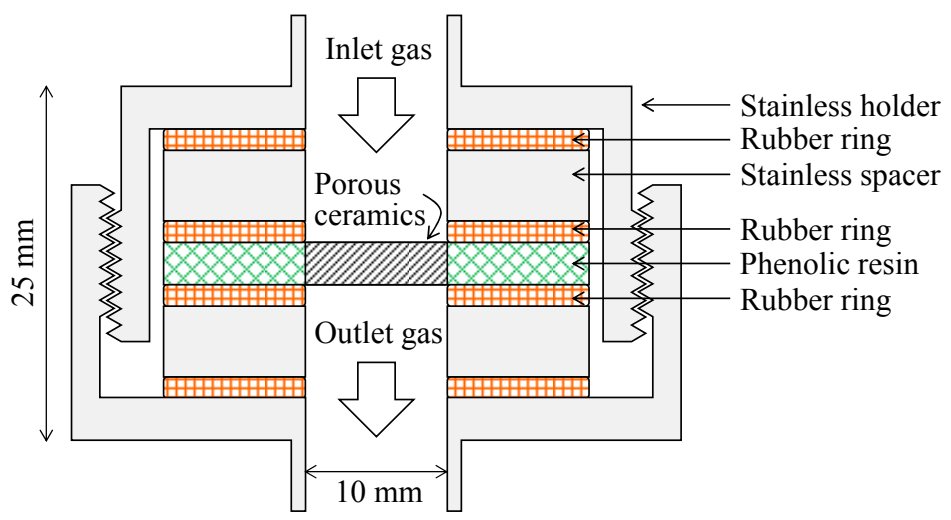

Figure 3. Gas permeation apparatus with porous ceramics.

\section{Results and Discussion}

\subsection{Microstructures of Porous Ceramics}

Figure 4 shows the microstructures and pore size distributions of $\mathrm{Al}_{2} \mathrm{O}_{3}$ and $\mathrm{YSZ}$ compacts measured by mercury porosimetry. The relative density and the open and closed porosities were $62.7 \%, 36.2 \%$, and $1.1 \%$, respectively, for $\mathrm{Al}_{2} \mathrm{O}_{3}$ and $50.4 \%, 40.5 \%$, and $9.1 \%$, respectively, for YSZ. The median pore sizes of $\mathrm{Al}_{2} \mathrm{O}_{3}$ and $\mathrm{YSZ}$ were 45.3 and $115.8 \mathrm{~nm}$, respectively. On the other hand, three-dimensional pore size was also determined on the observed microstructures (Figure $4 \mathrm{a}, \mathrm{b}$ ) by multiplying the two-dimensional pore size by 1.56 , as previously discussed $[16,19]$. The pore sizes at $10 \%$ and $90 \%$ of the cumulative frequency were 10.8 and $133.9 \mathrm{~nm}$, respectively, in porous $\mathrm{Al}_{2} \mathrm{O}_{3}$ and 8.2 and $113.1 \mathrm{~nm}$, respectively, in porous YSZ. The median sizes of the pores of $\mathrm{Al}_{2} \mathrm{O}_{3}$ and $\mathrm{YSZ}$ were 49.4 and $39.1 \mathrm{~nm}$, respectively. Compared to the pore size measured by microscopic technique, the pore size of mercury porosimetry was almost the same for the $\mathrm{Al}_{2} \mathrm{O}_{3}$ compact but was three times larger for the YSZ compact. In this paper, the pore size measured by mercury porosimetry was used to discuss the flux and permeability coefficient of the gas permeated through the porous ceramics.

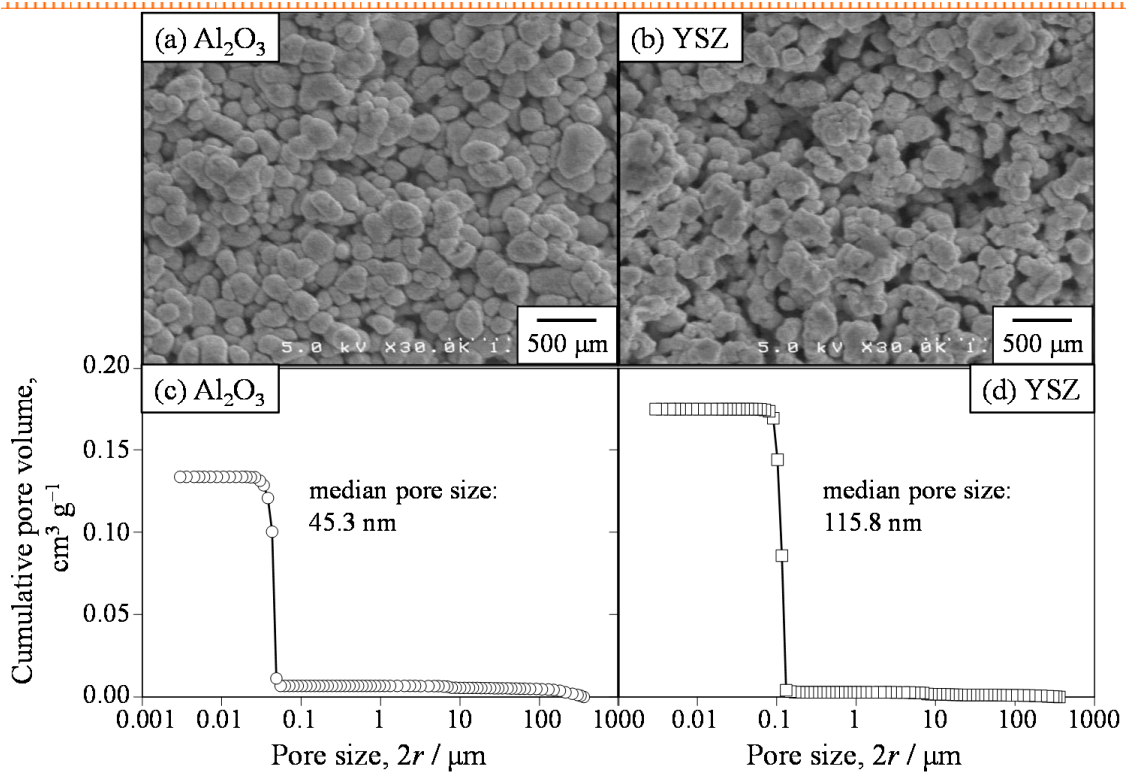

Figure 4. Microstructures $(\mathbf{a}, \mathbf{b})$ and pore size distributions $(\mathbf{c}, \mathbf{d})$ of $\mathrm{Al}_{2} \mathrm{O}_{3}$ and yttria-stabilized zirconia (YSZ) porous ceramics by mercury porosimetry. 
Figure 5 shows the microstructures and pore size distributions of $\mathrm{SiC}$ samples hot-pressed at 1400,1500 , and $1700{ }^{\circ} \mathrm{C}$. The relative density and the open and closed porosities of SiC samples were $61.1 \%, 36.1 \%$, and $2.8 \%$, respectively, at the hot-pressing temperature of $1400{ }^{\circ} \mathrm{C}, 69.3 \%, 28.1 \%$, and $2.6 \%$, respectively, at $1500{ }^{\circ} \mathrm{C}$, and $75.4 \%, 17.9 \%$, and $6.7 \%$, respectively, at $1700{ }^{\circ} \mathrm{C}$. The SiC samples densified through liquid-phase sintering consisted of bimodal particles smaller and larger than $1 \mu \mathrm{m}$. The fraction of larger particles increased at a higher hot-pressing temperature. Because the exact pore size distribution was difficult to measure on the basis of the scanning electron micrographs in Figure 5, the pore sizes were measured by mercury porosimetry. Figure $5 \mathrm{~d}$ shows the cumulative pore volume of the porous $\mathrm{SiC}$ compacts. The median sizes of the cumulative pore volume were 111.9, 113.8, and $164.0 \mathrm{~nm}$ in the $\mathrm{SiC}$ samples hot-pressed at 1400,1500 , and $1700{ }^{\circ} \mathrm{C}$, respectively. As a result, the pore size in the present experiment increased in the order $\mathrm{Al}_{2} \mathrm{O}_{3}<\mathrm{SiC} \approx \mathrm{YSZ}$.
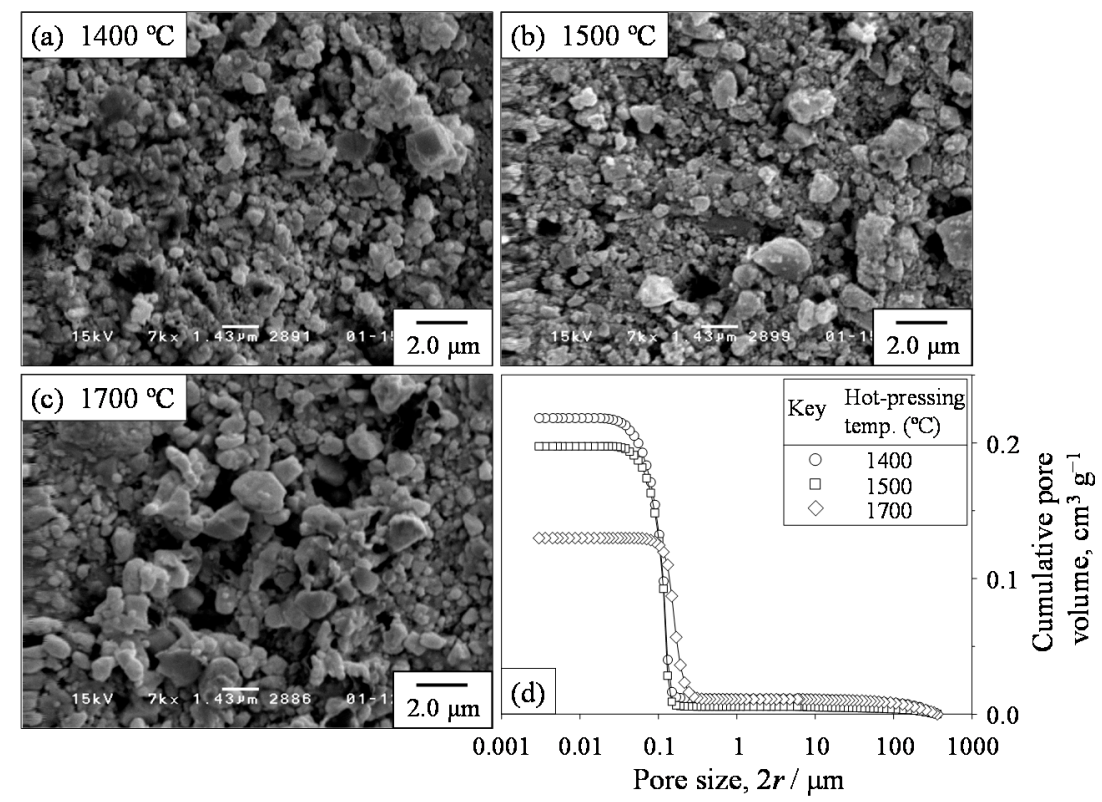

Figure 5. (a-c) Microstructures and (d) pore size distributions of $\mathrm{SiC}$ ceramics hot-pressed at (a) $1400^{\circ} \mathrm{C}$; (b) $1500{ }^{\circ} \mathrm{C}$; and (c) $1700{ }^{\circ} \mathrm{C}$.

\subsection{Permeation of $\mathrm{H}_{2}$ and $\mathrm{CO}_{2}$ Gases through Porous Ceramics}

Figures 6 and 7 show the single gas flux of $\mathrm{H}_{2}$ and $\mathrm{CO}_{2}$ through the $\mathrm{Al}_{2} \mathrm{O}_{3}$ and YSZ porous ceramics, respectively. The flux values for $\mathrm{H}_{2}$ and $\mathrm{CO}_{2}$ gases calculated via Equation (3) using the measured porosity and median pore size are also plotted in Figures 6 and 7. The permeation of $\mathrm{CO}_{2}$ gas in the porous $\mathrm{Al}_{2} \mathrm{O}_{3}$ and $\mathrm{YSZ}$ occurred above a critical pressure gradient. The gas flux then increased linearly with increasing pressure gradient. Compared with the flux and critical pressure gradient measured for $\mathrm{CO}_{2}$ gas, those measured for $\mathrm{H}_{2}$ were larger and smaller, respectively. The critical pressure gradient values of $\mathrm{H}_{2}$ and $\mathrm{CO}_{2}$ gases were 3.2 and $20.0 \mathrm{MPa} / \mathrm{m}$, respectively, for $\mathrm{Al}_{2} \mathrm{O}_{3}$ and 1.1 and $11.4 \mathrm{MPa} / \mathrm{m}$, respectively, for YSZ. The measured flux of $\mathrm{H}_{2}$ gas through the porous $\mathrm{Al}_{2} \mathrm{O}_{3}$ was similar to the calculated flux based on Knudsen flow (Equation (3)). The measured flux of $\mathrm{CO}_{2}$ gas was within the values calculated for Knudsen flow and Poiseuille flow. The Knudsen number $\left(=\lambda / r\right.$, Figure 1) was calculated to be 3.32-4.19 for $\mathrm{H}_{2}$ gas and 1.19-1.30 for $\mathrm{CO}_{2}$ gas; the exact values depend on the gas pressure (i.e., variation of the molecular mean free path in Figure 1), supporting the agreement between the experimental and the calculated transport characteristics of both gases. In the porous YSZ, the measured flux of $\mathrm{H}_{2}$ gas was close to the flux calculated using the Knudsen equation. Furthermore, the measured $\mathrm{CO}_{2}$ flux was within the values of $\mathrm{CO}_{2}$ flux calculated using the Knudsen and Poiseuille equations. 


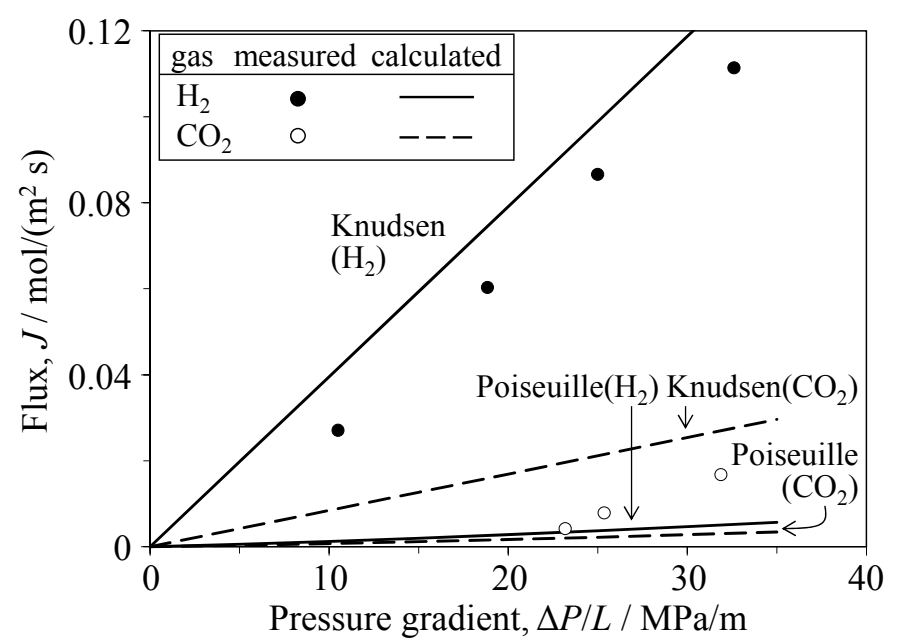

Figure 6. Single-gas flux of $\mathrm{H}_{2}$ and $\mathrm{CO}_{2}$ through $\mathrm{Al}_{2} \mathrm{O}_{3}$ porous ceramics as a function of the pressure gradient.

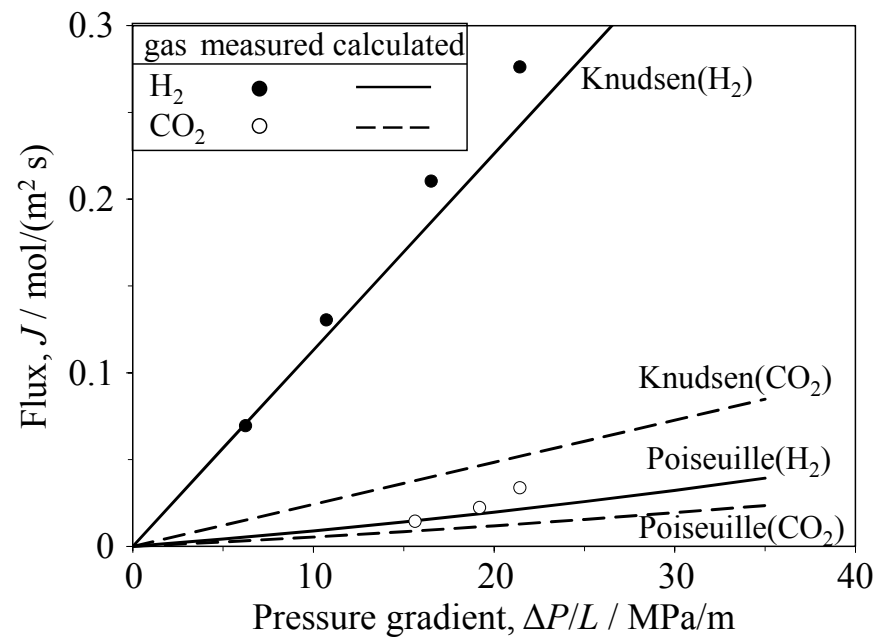

Figure 7. Single-gas flux of $\mathrm{H}_{2}$ and $\mathrm{CO}_{2}$ through $\mathrm{YSZ}$ porous ceramics as a function of the pressure gradient.

Similarly, Figure 8 shows the relationship between the single-gas flux of $\mathrm{H}_{2}$ and $\mathrm{CO}_{2}$ and the pressure gradient in the $\mathrm{SiC}$ porous ceramics. A similar trend of $\Delta P_{\mathrm{c}} / L$ (critical pressure gradient) for $\mathrm{H}_{2}$ and $\mathrm{CO}_{2}$ gases was observed in the porous $\mathrm{SiC}$ ceramics. The critical pressure gradient of $\mathrm{H}_{2}$ and $\mathrm{CO}_{2}$ gases was 0.2 and $2.4 \mathrm{MPa} / \mathrm{m}$, respectively, in the $\mathrm{SiC}$ hot-pressed at $1400{ }^{\circ} \mathrm{C}, 1.7$ and $8.5 \mathrm{MPa} / \mathrm{m}$, respectively, at $1500{ }^{\circ} \mathrm{C}$, and 0.8 and $2.8 \mathrm{MPa} / \mathrm{m}$, respectively, at $1700{ }^{\circ} \mathrm{C}$. Figure 9 and Table 1 summarize the permeability coefficients of $\mathrm{H}_{2}$ and $\mathrm{CO}_{2}$ gases as a function of the Knudsen number. The permeability coefficient was determined by dividing the flux $J$ by the effective pressure gradient $\left(\Delta P / L-\Delta P_{c} / L\right)$. Note that, because each $J-\Delta P / L$ plot for $\mathrm{H}_{2}$ and $\mathrm{CO}_{2}$ gases showed an intercept (i.e., a critical pressure gradient), the permeability coefficient was determined for the gas flow above the $\Delta P_{\mathrm{c}} / L$ value. The Knudsen number represents the molecular mean free path $(\lambda)$ normalized by the pore radius $(r)$. The molecular mean free path was calculated using Equation (7). The pore radii of the oxides and $\mathrm{SiC}$ were measured by mercury porosimetry, as described in Section 3.1. The measured permeability coefficients were compared with the permeability coefficients calculated using the Knudsen and Poiseuille equations. In the $\mathrm{Al}_{2} \mathrm{O}_{3}$ and $\mathrm{YSZ}$ porous ceramics, the permeability coefficients of both the $\mathrm{H}_{2}$ and $\mathrm{CO}_{2}$ gases were similar to those calculated using the Knudsen model. In the $\mathrm{SiC}$ porous ceramics, the measured permeability coefficient of $\mathrm{H}_{2}$ gas is well explained by the Knudsen model. The permeability coefficient of $\mathrm{CO}_{2}$ gas was within the values predicted by the Knudsen and Poiseuille models. When the Knudsen number $(\lambda / r)$ is greater than unity, Knudsen 
flow becomes the dominant gas transportation process, which is the usual tendency. As observed in Figure 9, when the Knudsen number decreases to a smaller value $(<1)$ in the $\mathrm{SiC}$ porous compacts, the influence of Poiseuille flow becomes larger in the case of $\mathrm{CO}_{2}$ gas.

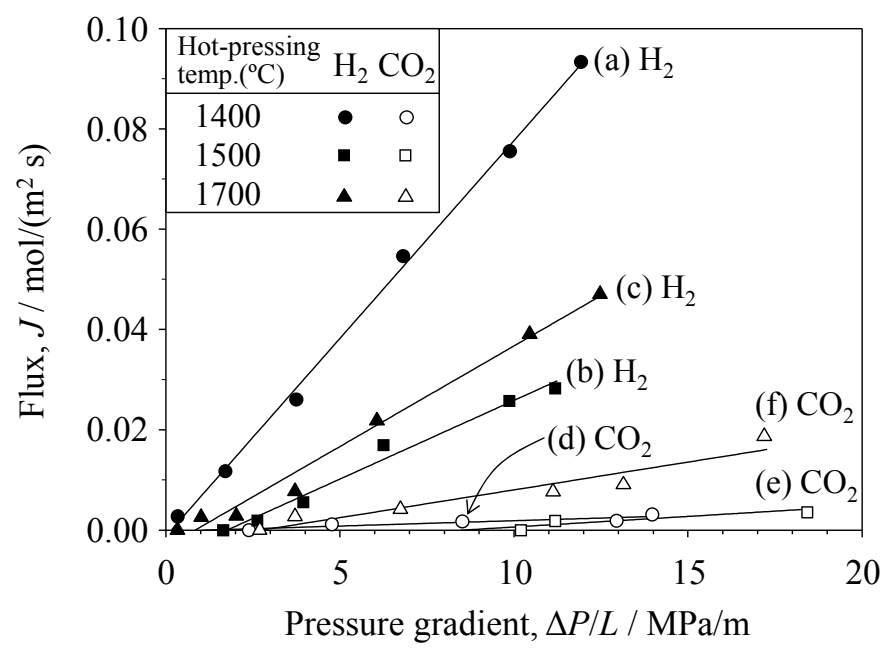

Figure 8. Single-gas flux of $\mathrm{H}_{2}$ and $\mathrm{CO}_{2}$ through porous $\mathrm{SiC}$ ceramics hot-pressed at 1400, 1500, and $1700{ }^{\circ} \mathrm{C}$ as a function of the pressure gradient.

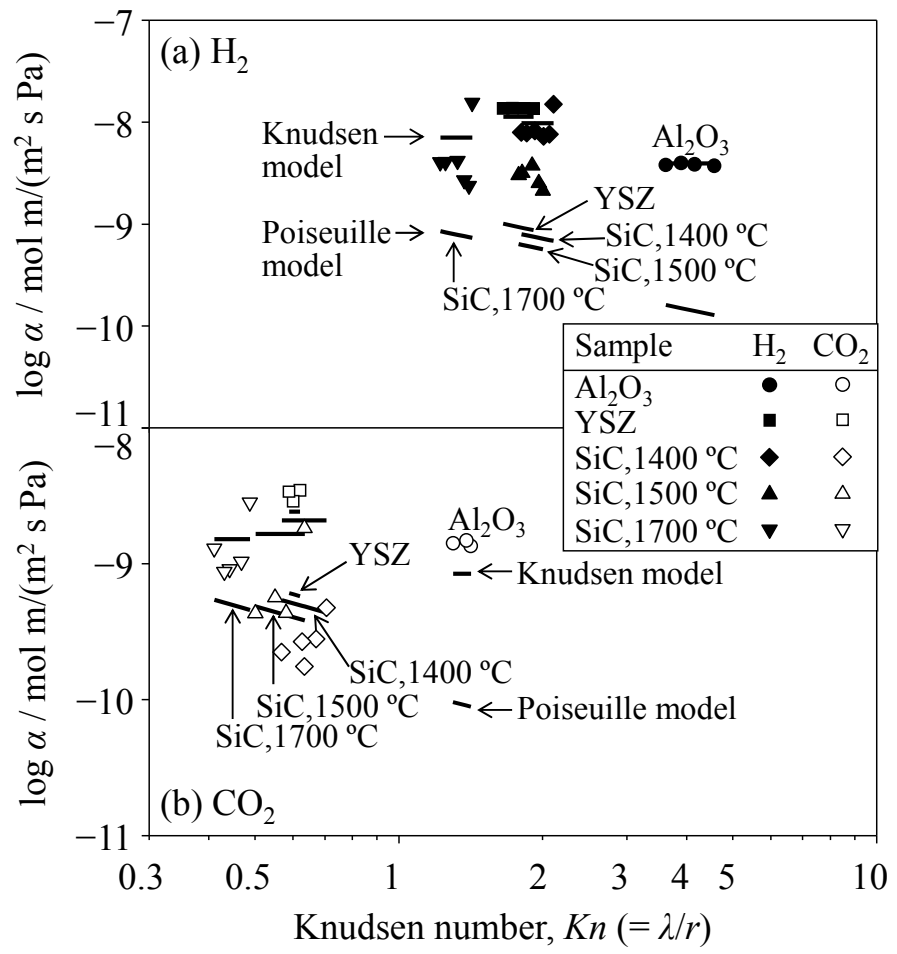

Figure 9. Permeability coefficients of (a) $\mathrm{H}_{2}$ gas and (b) $\mathrm{CO}_{2}$ gas in $\mathrm{Al}_{2} \mathrm{O}_{3}, \mathrm{YSZ}$, and $\mathrm{SiC}$ porous ceramics against the pressure gradient above the $\Delta P_{\mathrm{c}} / L$ value as a function of the Knudsen number.

Figure 10 shows the critical pressure gradient $\left(\Delta P_{c} / L\right)$ as a function of the Knudsen number $\left(\lambda / r\right.$ ratio). The $\Delta P_{\mathrm{c}} / L$ value increases at a small Knudsen number. This result implies that the $\Delta P_{\mathrm{c}} / L$ value is greater for $\mathrm{CO}_{2}$ gas with a small $\lambda$ value than for $\mathrm{H}_{2}$ gas with a large $\lambda$ value (Figure 1 ) in the same pore size distribution. Another observation is that the decreased pore size $(2 r)$ for a specified gas leads to an increase of the $\Delta P_{\mathrm{c}} / L$ value. That is, the $\Delta P_{\mathrm{c}} / L$ value increases in the case of Poiseuille 
flow giving a small flux of permeated gas rather than in the case of Knudsen flow giving a large flux of permeated gas (Figures 6 and 7). As evident in Figure 10a, the $\Delta P_{c} / L$ value is more sensitive to the Knudsen number in the case of the alumina porous ceramics than in the case of the SiC or YSZ porous ceramics. That is, the pore size, chemical composition of porous ceramics, and shape of pores (in $\mathrm{SiC}$ compacts) affect the $\Delta P_{\mathrm{c}} / L$ value. The large difference in $\Delta P_{\mathrm{c}} / L$ values between $\mathrm{H}_{2}$ and $\mathrm{CO}_{2}$ gases is effective to separate $\mathrm{H}_{2}$ gas from $\mathrm{CO}_{2}$ gas.

Table 1. Summary of permeability coefficients in Figure 9.

\begin{tabular}{|c|c|c|c|c|c|}
\hline \multirow{3}{*}{ Gas } & \multirow{3}{*}{ Sample } & \multirow{3}{*}{$\begin{array}{l}\text { Knudsen } \\
\text { Number }\end{array}$} & \multicolumn{3}{|c|}{ Permeability Coefficient $\left(10^{-9} \mathrm{~mol} \cdot \mathrm{m} /\left(\mathrm{m}^{2} \cdot \mathrm{s} \cdot \mathrm{Pa}\right)\right)$} \\
\hline & & & \multirow{2}{*}{ Measured } & \multicolumn{2}{|c|}{ Calculated } \\
\hline & & & & Knudsen & Poiseuille \\
\hline \multirow{5}{*}{$\mathrm{H}_{2}$} & $\mathrm{Al}_{2} \mathrm{O}_{3}$ & $3.62-4.57$ & $3.71-3.97$ & 3.96 & $0.13-0.16$ \\
\hline & YSZ & $1.65-1.91$ & $13.6-13.7$ & 11.3 & $0.87-1.01$ \\
\hline & $\mathrm{SiC}, 1400{ }^{\circ} \mathrm{C}$ & $1.80-2.11$ & $7.26-15.0$ & 9.75 & $0.68-0.80$ \\
\hline & $\mathrm{SiC}, 1500^{\circ} \mathrm{C}$ & $1.78-2.03$ & $2.12-3.75$ & 7.72 & $0.56-0.64$ \\
\hline & $\mathrm{SiC}, 1700^{\circ} \mathrm{C}$ & $1.22-1.44$ & $2.38-15.4$ & 7.08 & $0.73-0.86$ \\
\hline \multirow{5}{*}{$\mathrm{CO}_{2}$} & $\mathrm{Al}_{2} \mathrm{O}_{3}$ & $1.30-1.41$ & $1.35-1.48$ & 0.85 & $0.09-0.10$ \\
\hline & YSZ & $0.59-0.62$ & $2.88-3.47$ & 2.42 & 0.06 \\
\hline & $\mathrm{SiC}, 1400^{\circ} \mathrm{C}$ & $0.56-0.72$ & $0.18-0.48$ & 2.09 & $0.42-0.54$ \\
\hline & $\mathrm{SiC}, 1500^{\circ} \mathrm{C}$ & $0.50-0.64$ & $0.43-1.82$ & 1.65 & $0.38-0.49$ \\
\hline & $\mathrm{SiC}, 1700^{\circ} \mathrm{C}$ & $0.41-0.49$ & $0.87-2.82$ & 1.52 & $0.45-0.55$ \\
\hline
\end{tabular}

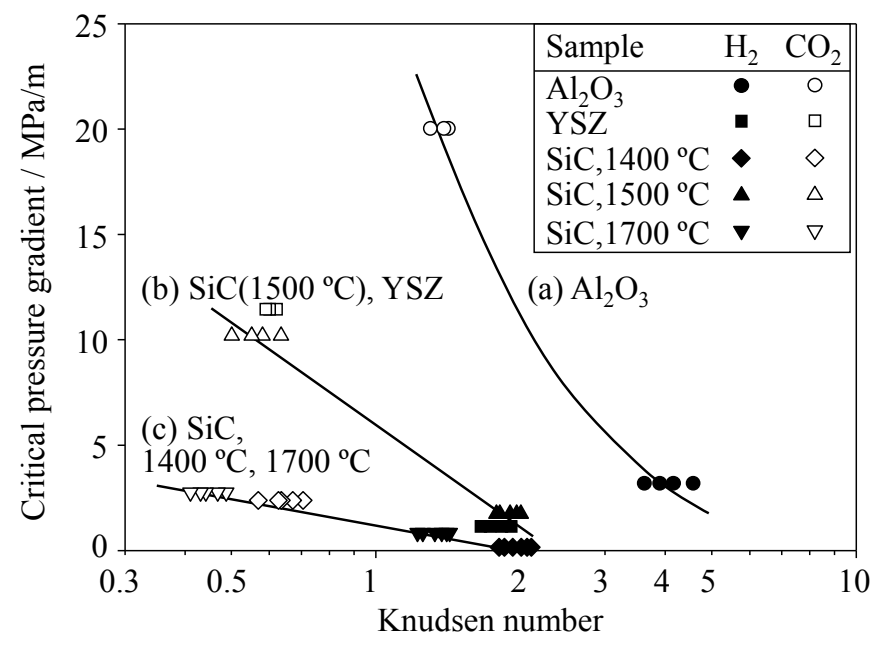

Figure 10. Relationship between the critical pressure gradient and the Knudsen number for (a) $\mathrm{Al}_{2} \mathrm{O}_{3}$, (b) $\mathrm{YSZ}$ and $\mathrm{SiC}$ sintered at $1500{ }^{\circ} \mathrm{C}$, and (c) SiC sintered at $1400{ }^{\circ} \mathrm{C}$ and $1700{ }^{\circ} \mathrm{C}$.

\subsection{Permeation of $\mathrm{H}_{2}-\mathrm{CO}_{2}$ Mixed Gas in Porous Ceramics}

Figure 11 shows the flux of $\mathrm{H}_{2}$ and $\mathrm{CO}_{2}$ gases for the mixed gas of $50 \mathrm{vol} \% \mathrm{H}_{2}$ and $50 \mathrm{vol} \% \mathrm{CO}_{2}$ in the $\mathrm{Al}_{2} \mathrm{O}_{3}$ and YSZ porous ceramics. For comparison, the flux values of $\mathrm{H}_{2}$ and $\mathrm{CO}_{2}$ single gases are also shown in Figure 11. In both of the porous ceramics, the flux of $\mathrm{H}_{2}$ gas was greater than that of $\mathrm{CO}_{2}$ gas. The flux of $\mathrm{H}_{2}$ gas in the mixed gas decreased substantially compared to that of single $\mathrm{H}_{2}$ gas. The critical pressure gradient $\left(\Delta P_{\mathrm{c}} / L\right)$ of $\mathrm{CO}_{2}$ gas in the mixed gas became smaller than that of single $\mathrm{CO}_{2}$ gas and approached that of single $\mathrm{H}_{2}$ gas. Figure 12 shows the flux of $\mathrm{H}_{2}$ and $\mathrm{CO}_{2}$ gases in the mixed gas permeated through the $\mathrm{SiC}$ porous ceramics. The flux values of $\mathrm{H}_{2}$ and $\mathrm{CO}_{2}$ gases were similar to each other and were similar in magnitude to the flux of single $\mathrm{H}_{2}$ gas. This tendency differs from the results shown in Figure 11. As previously mentioned, the $\mathrm{H}_{2}$ and $\mathrm{CO}_{2}$ single gases permeated through the $\mathrm{Al}_{2} \mathrm{O}_{3}$ or YSZ porous ceramics according to the Knudsen mechanism (Figure 9, Table 1). 
One factor used to interpret the permeation of the mixed gas is the interaction between pore walls and gas species, which is not expressed in the Knudsen equation (Equation (3)). The oxide porous ceramics have ionic bonds, and $\mathrm{CO}_{2}$ molecules are polarized between their carbon atom (delta plus) and oxygen atoms (delta minus) because of their different electronegativities. The attractive interaction between pore walls of porous oxide ceramics and $\mathrm{CO}_{2}$ molecules is expected to be strong compared to the interaction between pore walls and $\mathrm{H}_{2}$ molecules. The adsorption of $\mathrm{CO}_{2}$ molecules of the mixed gas on the pore walls of oxide ceramics may be interrupted by the collision between pore walls and $\mathrm{H}_{2}$ molecules, leading to a decrease in the critical pressure gradient of $\mathrm{CO}_{2}$ gas in the mixed gas.

On the basis of the data in Figures 11 and 12, Figure 13 shows the fraction of $\mathrm{H}_{2}$ gas in the outlet gas and the $\mathrm{H}_{2}$ fractions predicted by the Knudsen and Poiseuille models. In the $\mathrm{Al}_{2} \mathrm{O}_{3}$ and $\mathrm{YSZ}$ porous ceramics, the $\mathrm{H}_{2}$ fraction was higher than that of the supplied gas. When the pressure gradient decreased, the $\mathrm{H}_{2}$ fraction increased, reaching 0.966 at $6.16 \mathrm{MPa} / \mathrm{m}$ in the porous $\mathrm{Al}_{2} \mathrm{O}_{3}$ and 0.844 at $3.13 \mathrm{MPa} / \mathrm{m}$ in the porous YSZ, which exceeded the fraction of $\mathrm{H}_{2}$ predicted by the Knudsen equation. In the $\mathrm{SiC}$ porous ceramics, the $\mathrm{H}_{2}$ fraction was approximately the same value as in the supplied gas at pressure gradients greater than $10 \mathrm{MPa} / \mathrm{m}$. In the lower pressure-gradient range, the $\mathrm{H}_{2}$ fraction increased drastically. Within the detection limit of gas concentration (approximately $0.1 \%$ in this study), the $\mathrm{H}_{2}$ fraction reached almost unity at $1.36 \mathrm{MPa} / \mathrm{m}$.

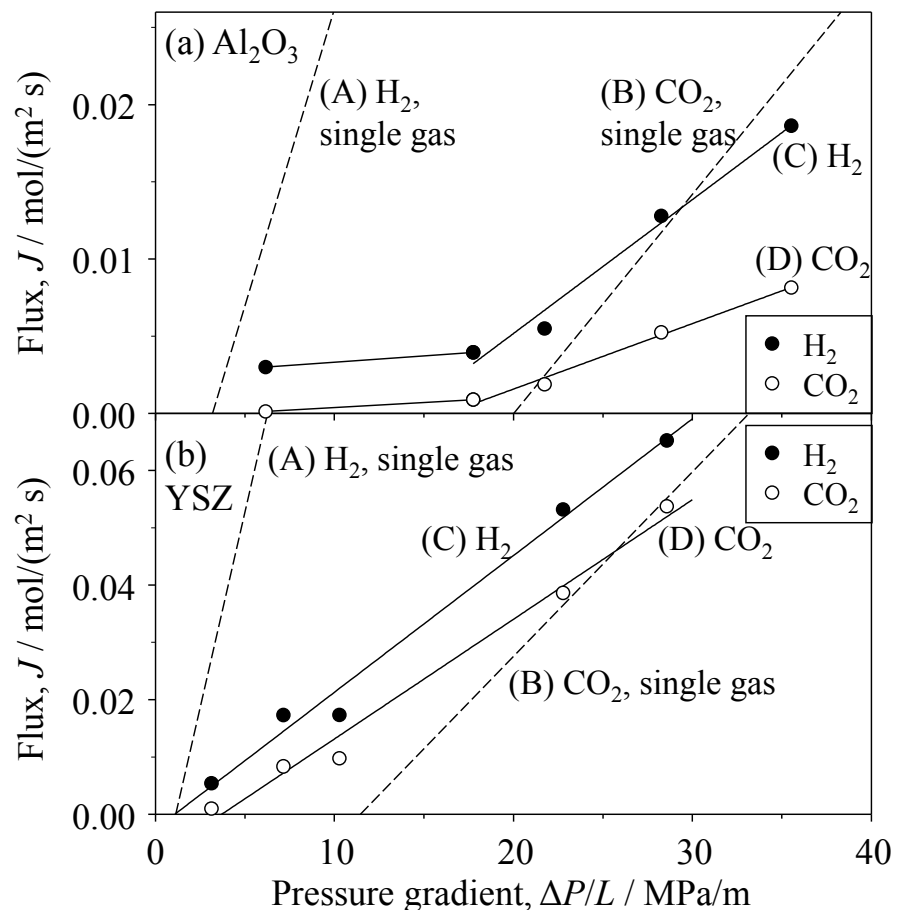

Figure 11. Flux of $\mathrm{H}_{2}$ and $\mathrm{CO}_{2}$ gases for the mixed gas of $50 \mathrm{vol} \% \mathrm{H}_{2}-50$ vol $\% \mathrm{CO}_{2}$ through (a) $\mathrm{Al}_{2} \mathrm{O}_{3}$ and (b) YSZ porous ceramics.

Figures 14 and 15 show the $\mathrm{H}_{2}$ fraction for 20 vol \% $\mathrm{H}_{2}-80 \mathrm{vol} \% \mathrm{CO}_{2}$ mixed gas and 80 vol \% $\mathrm{H}_{2}-20$ vol \% $\mathrm{CO}_{2}$ mixed gas, respectively. A similar increase of $\mathrm{H}_{2}$ fraction was measured at a low pressure gradient. In the case of $20 \% \mathrm{H}_{2}-80 \% \mathrm{CO}_{2}$ mixed gas (Figure 14), the $\mathrm{H}_{2}$ fraction was 0.972 at $6.88 \mathrm{MPa} / \mathrm{m}$ in $\mathrm{Al}_{2} \mathrm{O}_{3}, 0.504$ at $8.04 \mathrm{MPa} / \mathrm{m}$ in $\mathrm{YSZ}$, and 0.999 at $3.40 \mathrm{MPa} / \mathrm{m}$ in SiC, respectively. When $80 \% \mathrm{H}_{2}-20 \% \mathrm{CO}_{2}$ mixed gas was permeated (Figure 15), the $\mathrm{H}_{2}$ fraction was 0.976 at $7.61 \mathrm{MPa} / \mathrm{m}$ in $\mathrm{Al}_{2} \mathrm{O}_{3}, 0.936$ at $3.13 \mathrm{MPa} / \mathrm{m}$ in $\mathrm{YSZ}$, and 0.987 at $3.06 \mathrm{MPa} / \mathrm{m}$ in $\mathrm{SiC}$, respectively. These results are further discussed in a later section.

The selectivity is defined generally by Equation (6) in the Introduction; the selectivity for $50 \% \mathrm{H}_{2}-50 \% \mathrm{CO}_{2}$ mixed gas is included in Figure 16. The selectivity of all samples increased 
with decreasing pressure gradient. The selectivity of $\mathrm{Al}_{2} \mathrm{O}_{3}$ reached 28.8 at $6.16 \mathrm{MPa} / \mathrm{m}$, which is significantly higher than the reported selectivity of 3.9 at $\Delta P=0.1 \mathrm{MPa}$ and $100{ }^{\circ} \mathrm{C}$ in the case of an amorphous silica membrane with a thickness of $30 \mathrm{~nm}[6]$.

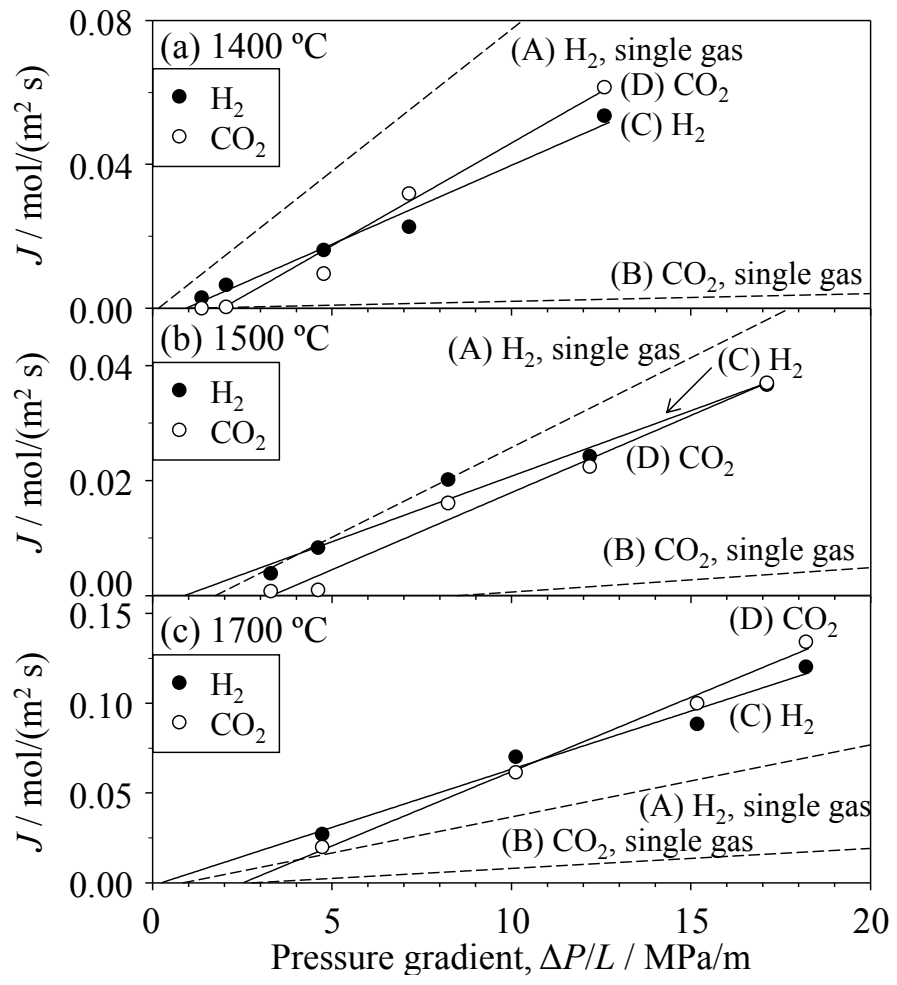

Figure 12. Flux of $\mathrm{H}_{2}$ and $\mathrm{CO}_{2}$ gases for the mixed gas of $50 \mathrm{vol} \% \mathrm{H}_{2}-50 \mathrm{vol} \% \mathrm{CO}_{2}$ through $\mathrm{SiC}$ ceramics hot-pressed at (a) $1400{ }^{\circ} \mathrm{C}$; (b) $1500^{\circ} \mathrm{C}$; and (c) $1700{ }^{\circ} \mathrm{C}$.

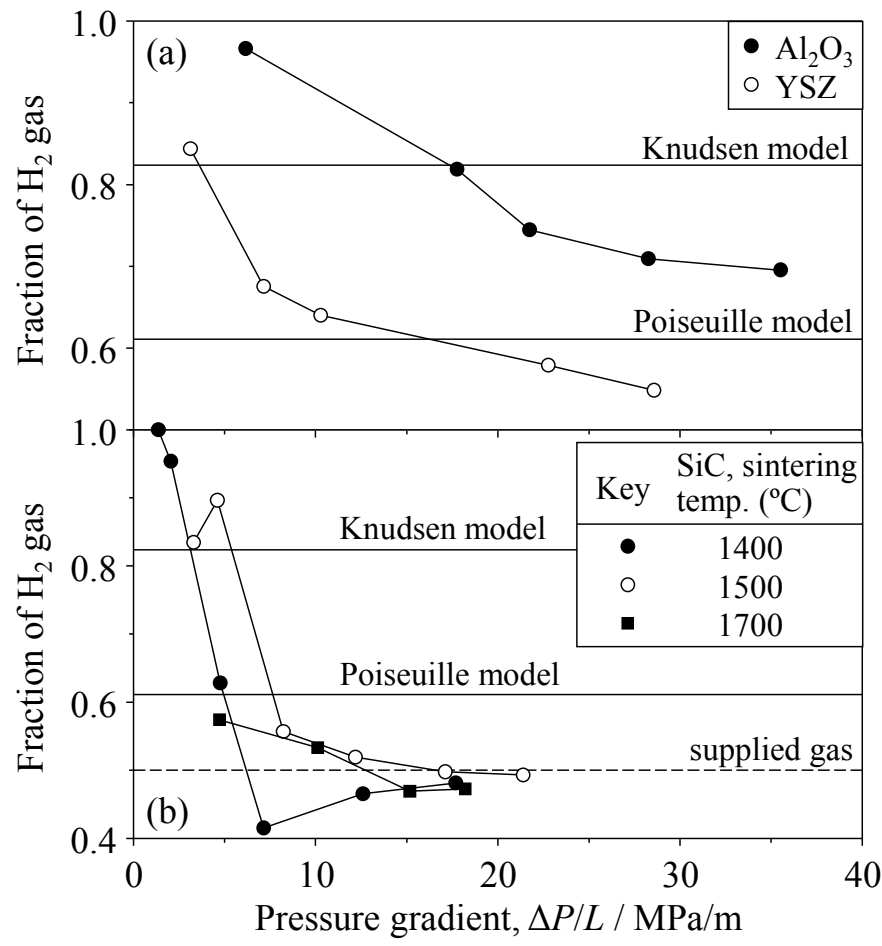

Figure 13. Fraction of $\mathrm{H}_{2}$ gas for the $50 \mathrm{vol} \% \mathrm{H}_{2}-50 \mathrm{vol} \% \mathrm{CO}_{2}$ mixed gas through (a) $\mathrm{Al}_{2} \mathrm{O}_{3}$ and $\mathrm{YSZ}$ and $(\mathbf{b}) \mathrm{SiC}$. 


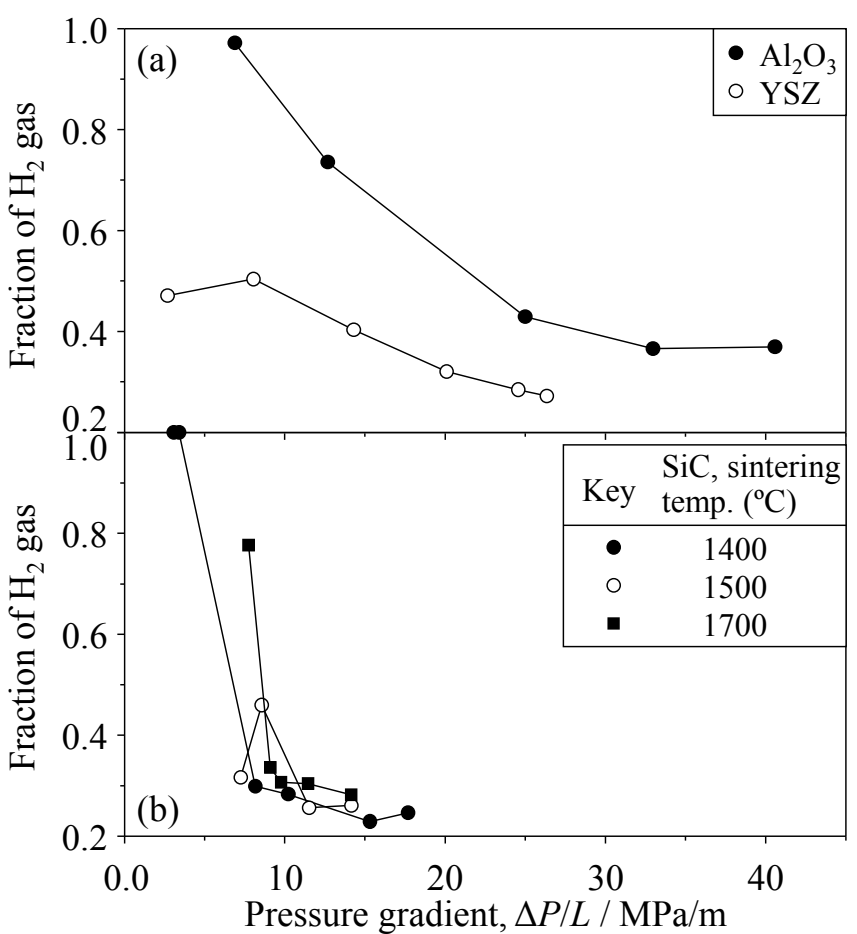

Figure 14. Fraction of $\mathrm{H}_{2}$ gas for the $20 \mathrm{vol} \% \mathrm{H}_{2}-80 \mathrm{vol} \% \mathrm{CO}_{2}$ mixed gas through (a) $\mathrm{Al}_{2} \mathrm{O}_{3}$ and YSZ and (b) SiC.

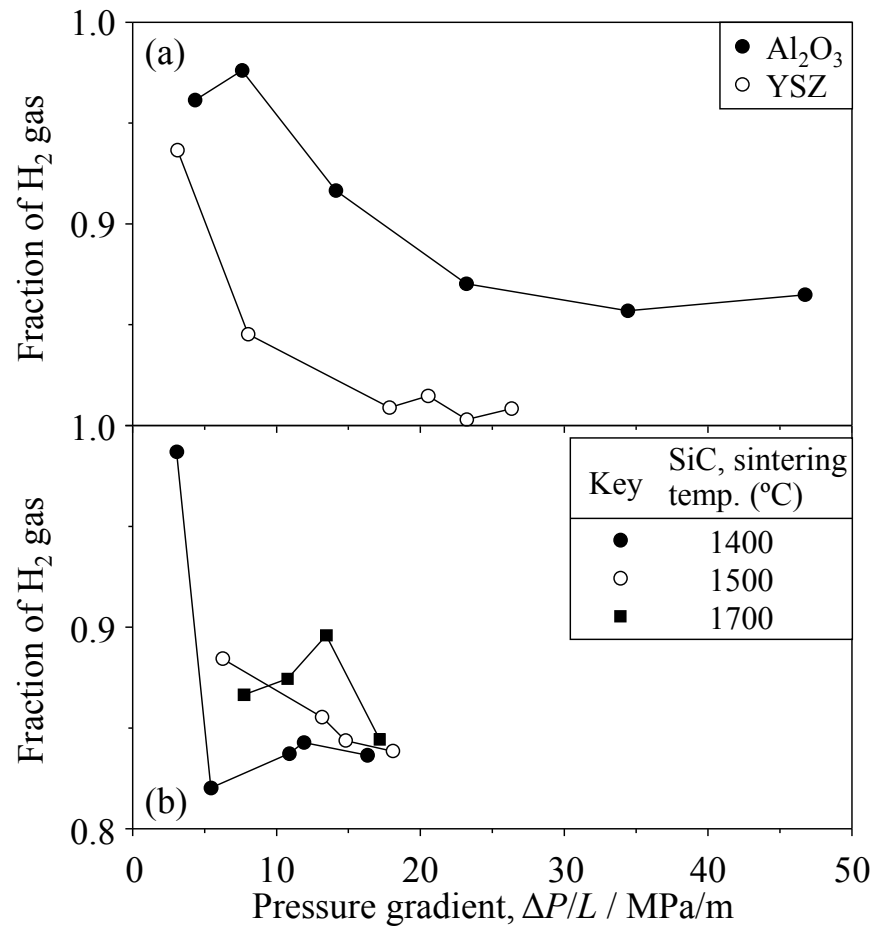

Figure 15. Fraction of $\mathrm{H}_{2}$ gas for the $80 \mathrm{vol} \% \mathrm{H}_{2}-20 \mathrm{vol} \% \mathrm{CO}_{2}$ mixed gas through (a) $\mathrm{Al}_{2} \mathrm{O}_{3}$ and YSZ and (b) $\mathrm{SiC}$. 


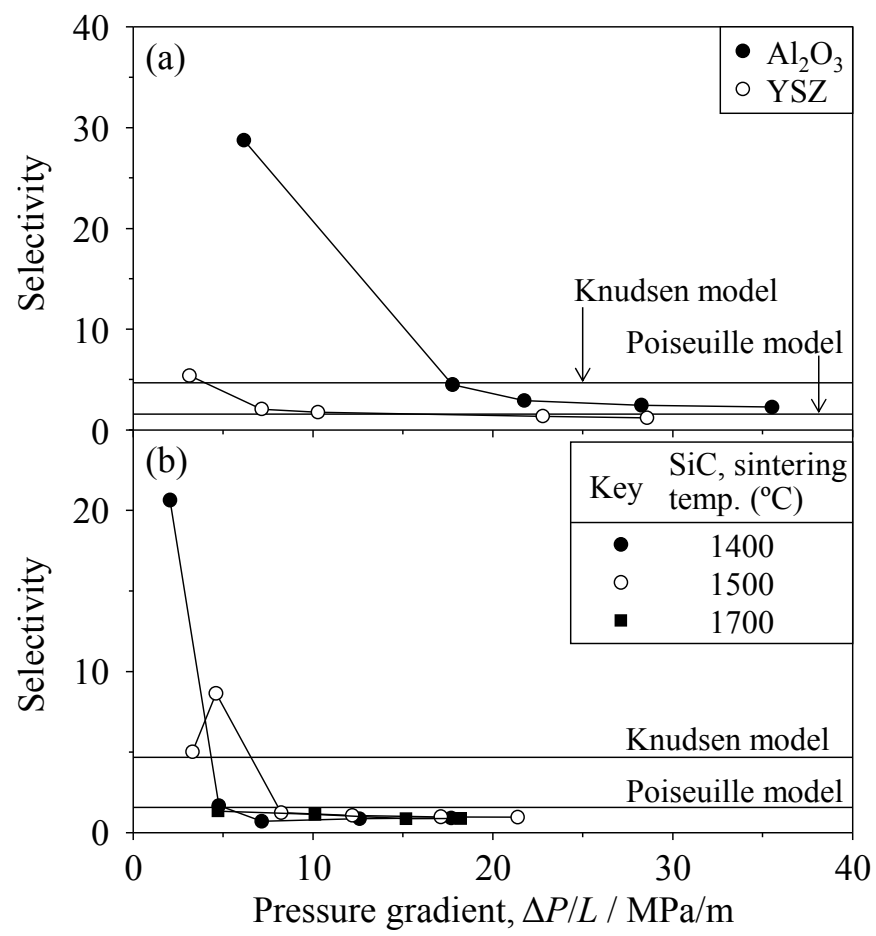

Figure 16. Selectivity (Equation (6)) of (a) $\mathrm{Al}_{2} \mathrm{O}_{3}$ and $\mathrm{YSZ}$; and (b) $\mathrm{SiC}$ for the $50 \mathrm{vol} \% \mathrm{H}_{2}-50$ vol \% $\mathrm{CO}_{2}$ mixed gas.

\subsection{Separation Model}

In the present porous ceramics, the critical pressure gradient was measured in the single-gas $\mathrm{H}_{2}$ and $\mathrm{CO}_{2}$ gas flows (Figure 10). This property is affected by the attractive interaction between the pore walls and the polarized gas molecules. Furthermore, the critical pressure gradient is closely related to the tortuous pore structure in the porous ceramics, which interrupts the smooth transportation of gas molecules [17]. In the Knudsen and Poiseuille models, straight pores parallel to the direction of gas flow are assumed to transport the inlet gas molecules. The flux of the $\mathrm{H}_{2}$ gas of the mixed gas in the Knudsen model was modified by Equation (8) using the critical pressure gradient $\left(\Delta P_{\mathrm{c}} / L\right)$ of single $\mathrm{H}_{2}$ gas flow:

$$
J\left(\mathrm{H}_{2}\right)=\frac{2 \varepsilon r \bar{c}\left(\mathrm{H}_{2}\right)}{3 R T} \frac{\Delta P(\operatorname{mix}) x}{L}\left(1-\frac{\Delta P_{\mathrm{c}}\left(\mathrm{H}_{2}\right)}{\Delta P(\operatorname{mix})}\right),
$$

where $\Delta P($ mix $)$ is the pressure gradient of mixed gas, $\bar{c}\left(\mathrm{H}_{2}\right)$ is the velocity of $\mathrm{H}_{2}$ molecules, and $x$ is the $\mathrm{H}_{2}$ gas fraction of the supplied mixed gas. This equation indicates that $J\left(\mathrm{H}_{2}\right)$ becomes $0 \mathrm{~mol} / \mathrm{s} \mathrm{m}^{2}$ at $x=0$ or $\Delta P(\operatorname{mix})=\Delta P_{\mathrm{c}}\left(\mathrm{H}_{2}\right)$. Similarly, Equation (9) represents the flux of $\mathrm{CO}_{2}$ molecules of the mixed gas in the modified Knudsen model:

$$
J\left(\mathrm{CO}_{2}\right)=\frac{2 \varepsilon r \bar{c}\left(\mathrm{CO}_{2}\right)}{3 R T} \frac{\Delta P(\operatorname{mix})(1-x)}{L}\left(1-\frac{\Delta P_{\mathrm{c}}\left(\mathrm{CO}_{2}\right)}{\Delta P(\operatorname{mix})}\right) .
$$

The $\mathrm{H}_{2}$ fraction is then expressed by Equation (10):

$$
F\left(\mathrm{H}_{2}\right)=\frac{J\left(\mathrm{H}_{2}\right)}{J\left(\mathrm{H}_{2}\right)+J\left(\mathrm{CO}_{2}\right)}=\frac{1}{1+\sqrt{\frac{M\left(\mathrm{H}_{2}\right)}{M\left(\mathrm{CO}_{2}\right)}} \frac{\left(\Delta P(\operatorname{mix})-\Delta P_{\mathrm{c}}\left(\mathrm{CO}_{2}\right)\right)}{\left(\Delta P(\operatorname{mix})-\Delta P_{\mathrm{c}}\left(\mathrm{H}_{2}\right)\right)} \frac{(1-x)}{x}} .
$$


Equation (10) indicates that $F\left(\mathrm{H}_{2}\right)$ approaches unity at $x=1$ and $\Delta P(\operatorname{mix})=\Delta P_{\mathrm{c}}\left(\mathrm{CO}_{2}\right)$. The flux values of $\mathrm{H}_{2}$ and $\mathrm{CO}_{2}$ molecules of the mixed gas in Poiseuille flow are modified by Equations (11) and (12), respectively:

$$
\begin{gathered}
J\left(\mathrm{H}_{2}\right)=\frac{r^{2} \varepsilon \bar{P}(\text { mix })}{8 R T \eta(\text { mix })} \frac{\Delta P(\text { mix }) x}{L}\left(1-\frac{\Delta P_{\mathrm{c}}\left(\mathrm{H}_{2}\right)}{\Delta P(\text { mix })}\right) \\
J\left(\mathrm{CO}_{2}\right)=\frac{\mathrm{r}^{2} \varepsilon \bar{P}(\text { mix })}{8 R T \eta(\text { mix })} \frac{\Delta P(\text { mix })(1-x)}{L}\left(1-\frac{\Delta P_{\mathrm{c}}\left(\mathrm{CO}_{2}\right)}{\Delta P(\text { mix })}\right) .
\end{gathered}
$$

In Equations (11) and (12), $\bar{P}(\mathrm{mix})$ is the average pressure between the inlet and outlet mixed gases, $\eta($ mix) is the viscosity of the mixed gas, and $\Delta P(\operatorname{mix}) / L$ is the pressure gradient between the inlet and outlet mixed gases. The $\mathrm{H}_{2}$ fraction in the Poiseuille model is given by Equation (13):

$$
F\left(\mathrm{H}_{2}\right)=\frac{1}{1+\frac{\left(\Delta P(\operatorname{mix})-\Delta P_{\mathrm{c}}\left(\mathrm{CO}_{2}\right)\right)}{\left(\Delta P(\operatorname{mix})-\Delta P_{\mathrm{c}}\left(\mathrm{H}_{2}\right)\right)} \frac{(1-x)}{x}} .
$$

Equation (13) approaches unity at $x=1$ and $\Delta P($ mix $)=\Delta P_{c}\left(\mathrm{CO}_{2}\right)$ and is similar to Equation (10). A specified pore provides different gas flow mechanisms for $\mathrm{H}_{2}$ and $\mathrm{CO}_{2}$ gases, as is evident in Figures 1 and 9. $\mathrm{H}_{2}$ gas with $\lambda / r>1$ and $\mathrm{CO}_{2}$ gas with $\lambda / r<1$ in a specified pore are treated as Knudsen and Poiseuille flows, respectively. The $\mathrm{H}_{2}$ fraction of the mixed gas in this pore is derived from Equations (8) and (12) and is expressed by Equation (14):

$$
F\left(\mathrm{H}_{2}\right)=\frac{1}{1+\frac{3 r \bar{P}(\operatorname{mix})}{16 \eta(\operatorname{mix}) \bar{c}\left(\mathrm{H}_{2}\right)} \frac{\left(\Delta P(\operatorname{mix})-\Delta P_{\mathrm{C}}\left(\mathrm{CO}_{2}\right)\right)}{\left(\Delta P(\operatorname{mix})-\Delta P_{\mathrm{c}}\left(\mathrm{H}_{2}\right)\right)} \frac{(1-x)}{x}}
$$

A commonality among Equations (10), (13) and (14) is the increase in the $F\left(\mathrm{H}_{2}\right)$ value at a small ratio of $J\left(\mathrm{CO}_{2}\right) / J\left(\mathrm{H}_{2}\right)$. This is discussed in the introduction and is seen in the calculated gas flux in Figure 6 or Figure 7. The theoretical $\mathrm{H}_{2}$ fraction increases in the order of Equation (13) (Poiseuille model) < Equation (10) (Knudsen model) < Equation (14) (Knudsen model for $\mathrm{H}_{2}$ gas, Poiseuille model for $\mathrm{CO}_{2}$ gas). That is, the specified pore giving Equation (14) exerts a kind of sieving effect for $\mathrm{CO}_{2}$ gas in the mixed gas. The previous discussion indicates that the following factors are key to increasing the $\mathrm{H}_{2}$ selectivity: (1) a large difference of $\Delta P_{\mathrm{c}}$ for $\mathrm{H}_{2}$ and $\mathrm{CO}_{2}$ gases $\left(\Delta P_{\mathrm{c}}\left(\mathrm{CO}_{2}\right)>>\Delta P_{\mathrm{c}}\left(\mathrm{H}_{2}\right)\right)$, which is closely related to the tortuous pore structure, chemical composition of material, and Knudsen number (Figure 10); (2) a specified pore giving Knudsen flow for $\mathrm{H}_{2}$ gas and Poiseuille flow for $\mathrm{CO}_{2}$ gas (Figures 1 and 9); and (3) attractive interactions between the pore walls and the specified gas molecules $\left(\mathrm{CO}_{2}\right)$. In this paper, Factor (3) is not examined with sufficient experimental data.

Figures 17 and 18 show comparisons between measured and calculated $\mathrm{H}_{2}$ fractions in the $\mathrm{Al}_{2} \mathrm{O}_{3}$ porous ceramics and $\mathrm{SiC}$ porous ceramics, respectively. In the calculation of Equation (14), $\eta($ mix $)$ is approximated by $\eta\left(\mathrm{H}_{2}\right) x+\eta\left(\mathrm{CO}_{2}\right)(1-x)$. As is evident in Figures 17 and 18, the calculated $F\left(\mathrm{H}_{2}\right)$ lines for Equations (10), (13) and (14) increase in the order Equation (13) < Equation $(10)<$ Equation (14) with decreasing pressure gradient. The three calculated $F\left(\mathrm{H}_{2}\right)$ lines of the mixed gas explain the general tendency of the experimental results. The discrepancy of $\Delta P / L$ values at $F\left(\mathrm{H}_{2}\right)=1$ between the calculation and experiment in Figure 17 is related to the decrease of $\Delta P_{c}\left(\mathrm{CO}_{2}\right)$ for the mixed gas as compared with single $\mathrm{CO}_{2}$ gas (Figure 11). The condition of $\Delta P_{\mathrm{c}}\left(\mathrm{CO}_{2}\right) \approx \Delta P_{\mathrm{c}}\left(\mathrm{H}_{2}\right)$ in Equations (10), (13) and (14) implies no dependence of $F\left(\mathrm{H}_{2}\right)$ on $\Delta P(\operatorname{mix})$ and gives a constant $F\left(\mathrm{H}_{2}\right)$ value that depends on the gas flow mechanism and the inlet gas composition (e.g., $F\left(\mathrm{H}_{2}\right)=0.5$ in Equation (13), $F\left(\mathrm{H}_{2}\right)=0.824$ in Equation (10), and $F\left(\mathrm{H}_{2}\right)=0.967$ in Equation (14) for $x=0.5$ ). The measured range of the $\mathrm{H}_{2}$ fraction for a constant $x$ value in Figure 17 or Figure 18 was almost in agreement with the range calculated via Equation (13). This similarity suggests that (1) the mixed gas in the $\mathrm{Al}_{2} \mathrm{O}_{3}$ or $\mathrm{SiC}$ porous ceramics flows via the Poiseuille mechanism; (2) the flow mechanism of the mixed gas is controlled by $\mathrm{CO}_{2}$ gas with a small Knudsen number (Figure 9); and (3) the Knudsen flow 
of single $\mathrm{H}_{2}$ gas with a high Knudsen number is greatly influenced in the mixed gas by the coexisting $\mathrm{CO}_{2}$ molecules with a short molecular mean free path. Therefore, the molecular mean free path of $\mathrm{H}_{2}$ molecules is reduced by mixed $\mathrm{CO}_{2}$ molecules. That is, Equation (13) is able to explain the $\mathrm{H}_{2}$ fraction of the mixed gas under Poiseuille flow.

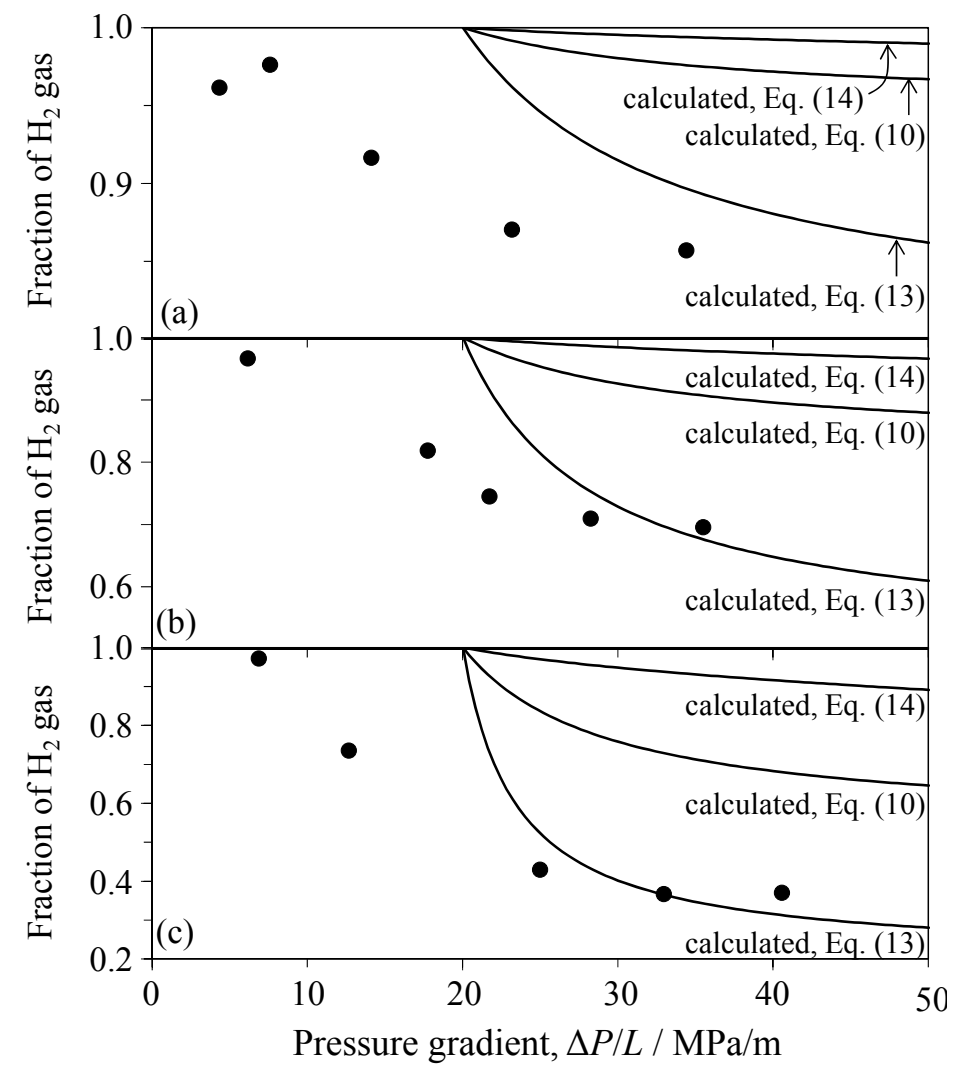

Figure 17. Comparison between measured and calculated $\mathrm{H}_{2}$ fractions in the porous $\mathrm{Al}_{2} \mathrm{O}_{3}$ ceramics for the supplied gas of (a) $80 \mathrm{vol} \% \mathrm{H}_{2}-20 \mathrm{vol} \% \mathrm{CO}_{2} ;$ (b) $50 \mathrm{vol} \% \mathrm{H}_{2}-50 \mathrm{vol} \% \mathrm{CO}_{2}$, and (c) $20 \mathrm{vol} \%$ $\mathrm{H}_{2}-80$ vol \% $\mathrm{CO}_{2}$.

\section{Reliability of Experiment}

To demonstrate the reproducibility of the gas separation experiment, the experiments were repeated for another three $\mathrm{Al}_{2} \mathrm{O}_{3}$ samples with $59.3 \%-61.2 \%$ relative densities, which were sintered at $800{ }^{\circ} \mathrm{C}$ for $1 \mathrm{~h}$. Figure 19 shows the typical flux values of the $\mathrm{H}_{2}$ and $\mathrm{CO}_{2}$ gases through the porous $\mathrm{Al}_{2} \mathrm{O}_{3}$ compact of $60.9 \%$ relative density (sample No. 4 in Figure 20) for the $50 \% \mathrm{H}_{2}-50 \% \mathrm{CO}_{2}$ mixed inlet gas with and without moisture $\left(3 \mathrm{vol} \% \mathrm{H}_{2} \mathrm{O}\right)$. The humidification of the supplied gas was carried out by bubbling the mixed gas in distilled water at $25^{\circ} \mathrm{C}$. When the dried gas was supplied, the flux of $\mathrm{H}_{2}$ gas decreased by mixing as compared with the flux of single $\mathrm{H}_{2}$ gas. However, the $\mathrm{CO}_{2}$ gas flux of the mixed gas was not affected by coexisting $\mathrm{H}_{2}$ gas. These results were similar to the result shown in Figure 11. The critical pressure gradient of $\mathrm{CO}_{2}$ gas depended on the $\mathrm{Al}_{2} \mathrm{O}_{3}$ sample used. In $70 \%$ of the total 20 experiments using the different four $\mathrm{Al}_{2} \mathrm{O}_{3}$ samples, including the sample in Section 3, for several supplied gas compositions, the critical pressure gradient was observed for $\mathrm{H}_{2}$ and $\mathrm{CO}_{2}$ gases. Figure 20 shows the fraction of $\mathrm{H}_{2}$ gas permeated through the different four $\mathrm{Al}_{2} \mathrm{O}_{3}$ samples sintered at $800{ }^{\circ} \mathrm{C}$. In two samples (Nos. 1 and 2), the $\mathrm{H}_{2}$ fraction increased with a decrease in the pressure gradient. The other two samples (Nos. 3 and 4) exhibited no dependence of $\mathrm{H}_{2}$ fraction on pressure gradient, but the $\mathrm{H}_{2}$ fraction of sample No. 3 was 10\%-25\% higher than that of the supplied gas. Therefore, in $75 \%$ of the experiments with the different four samples and several supplied gas compositions, the fraction of permeated $\mathrm{H}_{2}$ gas increased up to $16 \%-76 \%$ from 
the $\mathrm{H}_{2}$ fraction of the supplied gas. The influence of moisture in the porous compact or in the $\mathrm{H}_{2}-\mathrm{CO}_{2}$ mixed gas was investigated using sample No. $4, \mathrm{Al}_{2} \mathrm{O}_{3}(60.9 \%$ relative density) in Figures 19 and 21. When the humidified $\mathrm{H}_{2}-\mathrm{CO}_{2}$ mixed gas was supplied to sample No. $4, \mathrm{Al}_{2} \mathrm{O}_{3}$, the dependence of the $\mathrm{CO}_{2}$ gas flux on the pressure gradient (Figure 19b) was similar to the trend described in Section 3.3 (Figure 11). That is, the $\mathrm{CO}_{2}$ gas flux decreased rapidly with decreasing pressure gradient. In the dried gas condition, the $\mathrm{H}_{2}$ fraction was almost the same as that of supplied gas in the pressure gradient range from 2.0 to $37.8 \mathrm{MPa} / \mathrm{m}$ (Figure 21). In the humidified condition, the fraction of $\mathrm{H}_{2}$ gas, which was measured 2-6 times at each pressure gradient, was significantly scattered but the $\mathrm{H}_{2}$ fraction was apparently enhanced as compared to the dried gas condition. The maximum $\mathrm{H}_{2}$ fraction was 0.331 , 0.905 , and 0.986 when the supplied gas contained $20 \%, 50 \%$, and $80 \% \mathrm{H}_{2}$, respectively. Therefore, the moisture in the experimental condition adsorbs easily on the present porous ceramics, as described in the experimental section, and affects the selectivity of the supplied $\mathrm{H}_{2}-\mathrm{CO}_{2}$ mixed gas. After the experiment with the humidified gas in Figure 21, a slight weight gain of $0.034 \%$ was measured. That is, the scattered data of the gas separation in Figure 21 are caused by the structure of porous ceramics (tortuosity and size distribution of pores, and porosity) and interaction between gas molecules and pore wall (i.e., ceramics particles), which is affected by the moisture adsorbed on the porous ceramics or included in the supplied gas.

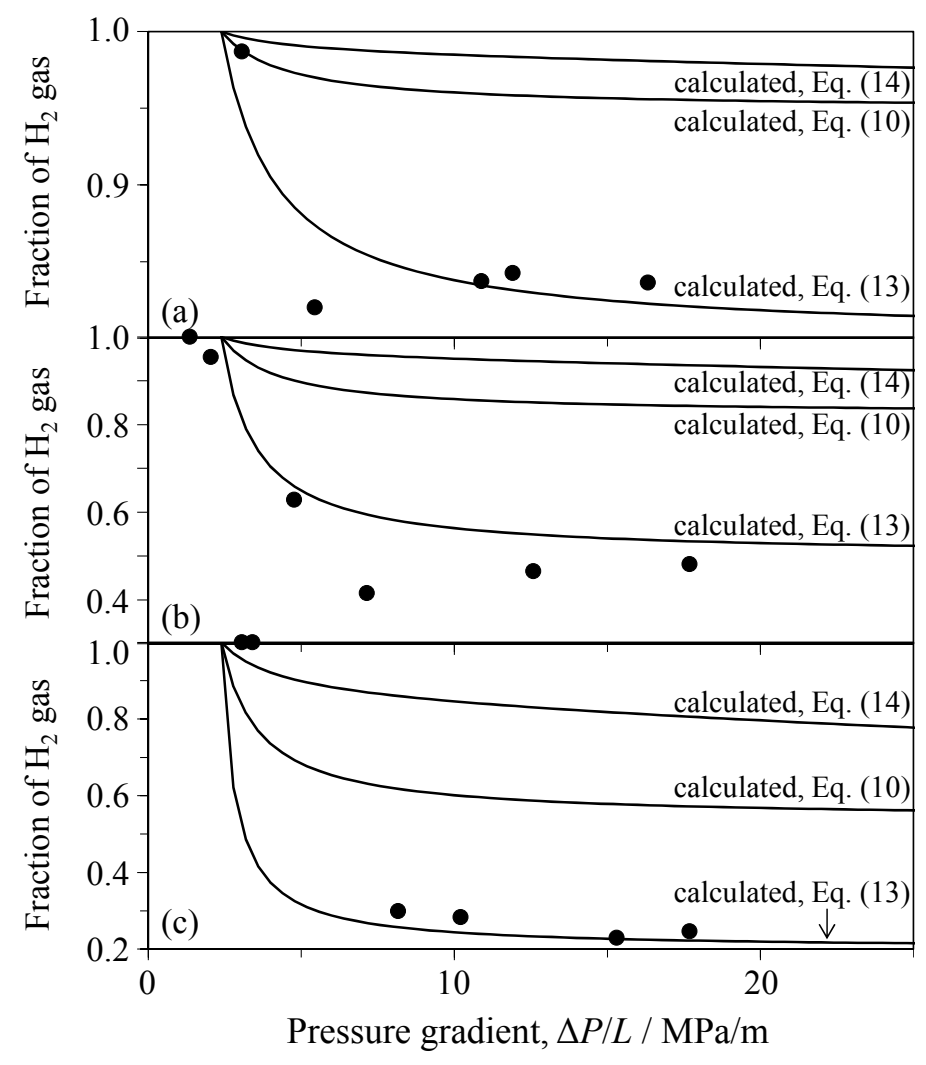

Figure 18. Comparison between measured and calculated $\mathrm{H}_{2}$ fractions in the porous $\mathrm{SiC}$ ceramics hot-pressed at $1400{ }^{\circ} \mathrm{C}$ for the supplied gas of (a) $80 \mathrm{vol} \% \mathrm{H}_{2}-20 \mathrm{vol} \% \mathrm{CO}_{2}$; (b) $50 \mathrm{vol} \% \mathrm{H}_{2}-50 \mathrm{vol} \%$ $\mathrm{CO}_{2}$; and (c) $20 \mathrm{vol} \% \mathrm{H}_{2}-80 \mathrm{vol} \% \mathrm{CO}_{2}$. 


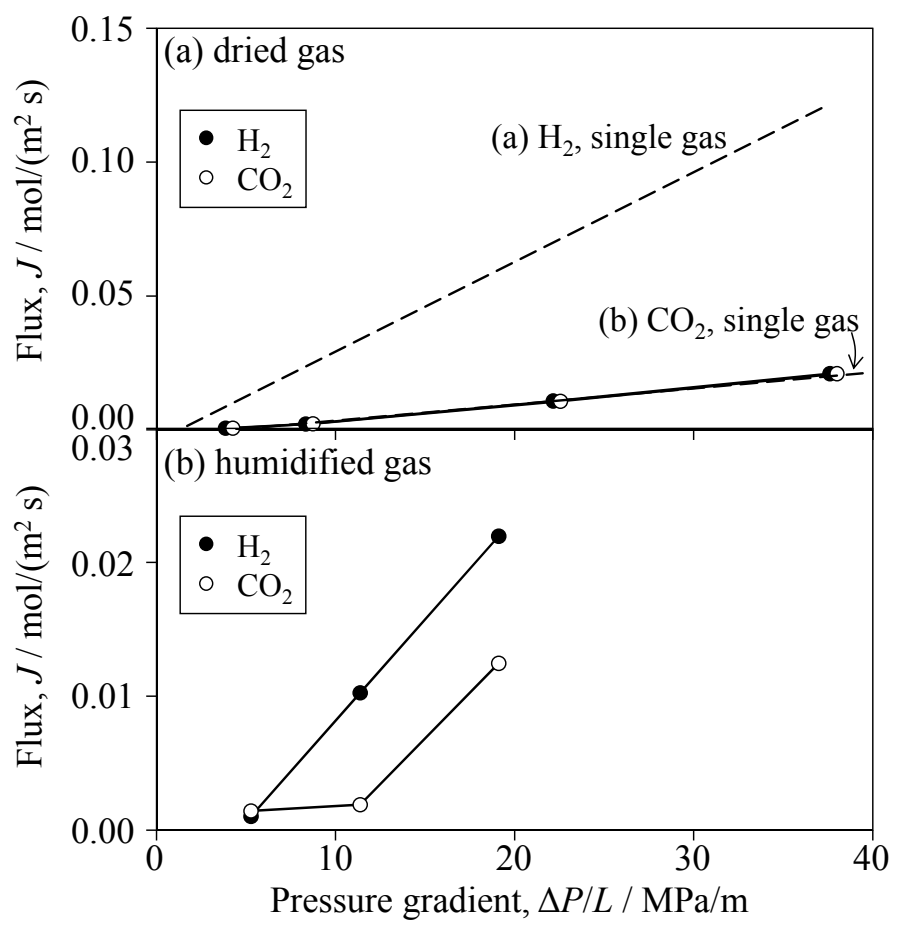

Figure 19. Flux of $\mathrm{H}_{2}$ and $\mathrm{CO}_{2}$ gases permeated through $\mathrm{Al}_{2} \mathrm{O}_{3}$ porous ceramics (60.9\% relative density) for the $50 \mathrm{vol} \% \mathrm{H}_{2}-50 \mathrm{vol} \% \mathrm{CO}_{2}$ mixed gas (a) with and (b) without $3 \mathrm{vol} \% \mathrm{H}_{2} \mathrm{O}$.

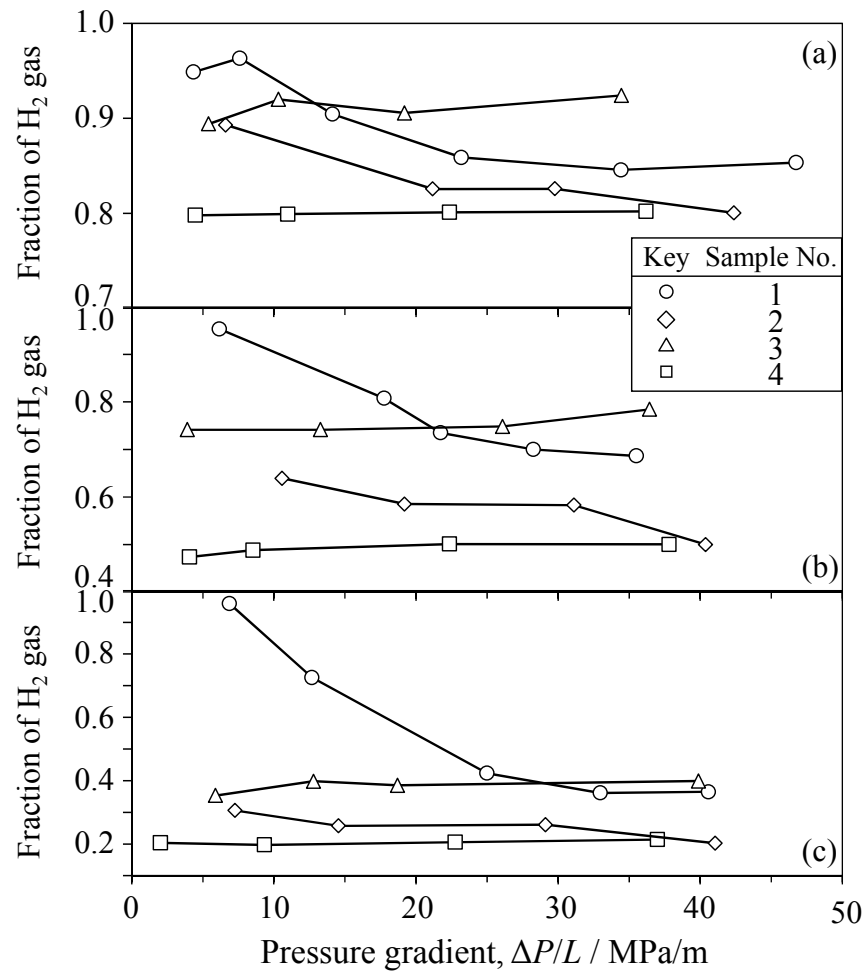

Figure 20. $\mathrm{H}_{2}$ fractions through the different four samples of $\mathrm{Al}_{2} \mathrm{O}_{3}$ sintered at $800{ }^{\circ} \mathrm{C}$ for the dried gas of (a) $80 \mathrm{vol} \% \mathrm{H}_{2}-20 \mathrm{vol} \% \mathrm{CO}_{2}$; (b) $50 \mathrm{vol} \% \mathrm{H}_{2}-50 \mathrm{vol} \% \mathrm{CO}_{2}$ and (c) $20 \mathrm{vol} \% \mathrm{H}_{2}-80 \mathrm{vol} \% \mathrm{CO}_{2}$. 


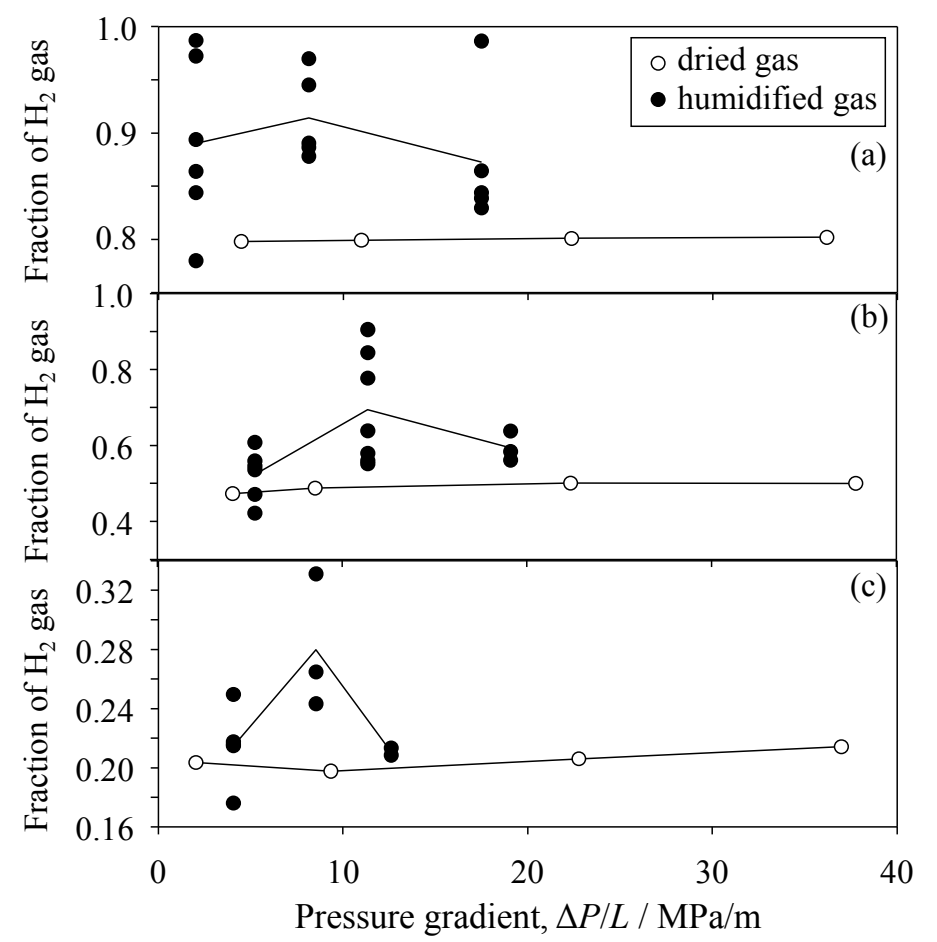

Figure 21. Influence of humidification of supplied gas of (a) $80 \mathrm{vol} \% \mathrm{H}_{2}-20 \mathrm{vol} \% \mathrm{CO}_{2} ;$ (b) $50 \mathrm{vol} \%$ $\mathrm{H}_{2}-50 \mathrm{vol} \% \mathrm{CO}_{2}$ and (c) $20 \mathrm{vol} \% \mathrm{H}_{2}-80 \mathrm{vol} \% \mathrm{CO}_{2}$ on the $\mathrm{H}_{2}$ fractions through the porous $\mathrm{Al}_{2} \mathrm{O}_{3}$ ceramics $(60.9 \%$ relative density, sample No. 4 in Figure 20).

\section{Conclusions}

Porous ceramics of $\alpha$-alumina, yttria-stabilized zirconia (YSZ), and silicon carbide were fabricated, and their permeability toward hydrogen, carbon dioxide, and hydrogen-carbon dioxide mixtures was investigated. The open porosity and median pore size of the fabricated porous ceramics were $36.2 \%$ and $45.3 \mathrm{~nm}$ for $\mathrm{Al}_{2} \mathrm{O}_{3}, 40.5 \%$ and $115.8 \mathrm{~nm}$ for $\mathrm{YSZ}$, and $17.9 \%-36.1 \%$ and $111.9-164.0 \mathrm{~nm}$ for $\mathrm{SiC}$ samples hot-pressed at $1400-1700{ }^{\circ} \mathrm{C}$, respectively. The permeation of single $\mathrm{H}_{2}$ or $\mathrm{CO}_{2}$ gas occurred above a critical pressure gradient and increased linearly with an increasing pressure gradient. A higher flux and a lower critical pressure gradient were measured for $\mathrm{H}_{2}$ gas than for $\mathrm{CO}_{2}$ gas. In the $\mathrm{Al}_{2} \mathrm{O}_{3}$ and YSZ porous ceramics, the permeability coefficients of both $\mathrm{H}_{2}$ and $\mathrm{CO}_{2}$ gases were similar to those predicted by the Knudsen model. In the $\mathrm{SiC}$ porous ceramics, the measured permeability coefficient of $\mathrm{H}_{2}$ gas was explained by the Knudsen model, and the permeability coefficient of $\mathrm{CO}_{2}$ gas was within the range based on values calculated by the Knudsen and Poiseuille models. The aforementioned results are explained by the Knudsen number $(\lambda / r$ ratio, $\lambda$ : molecular mean free path of gas molecules, $r$ : pore radius). When the Knudsen number is larger than unity, Knudsen flow becomes a dominant gas transportation process. In the nanometer-sized tortuous pore structure, the composition of material and the Knudsen number $\left(\lambda / r\right.$ ratio) affect the critical pressure gradient of a single gas of $\mathrm{H}_{2}$ or $\mathrm{CO}_{2}$. The critical pressure gradient increases more with decreasing Knudsen number in the case of $\mathrm{Al}_{2} \mathrm{O}_{3}$ than in the case of SiC.

In the permeation of the mixed gas of $50 \mathrm{vol} \% \mathrm{H}_{2}-50 \mathrm{vol} \% \mathrm{CO}_{2}$, the $\mathrm{H}_{2}$ flux value in $\mathrm{Al}_{2} \mathrm{O}_{3}$ or YSZ became smaller than that of single $\mathrm{H}_{2}$ gas and approached that of single $\mathrm{CO}_{2}$ gas. By contrast, the $\mathrm{CO}_{2}$ flux in the mixed gas through $\mathrm{SiC}$ ceramics became larger than that of single $\mathrm{CO}_{2}$ gas and approached the flux of single $\mathrm{H}_{2}$ gas. The fraction of $\mathrm{H}_{2}$ gas through the $\mathrm{Al}_{2} \mathrm{O}_{3}$ and $\mathrm{YSZ}$ compacts became higher than the mixing ratio of the supplied gas and increased with decreasing pressure gradient, reaching 0.966 at $6.16 \mathrm{MPa} / \mathrm{m}$ in $\mathrm{Al}_{2} \mathrm{O}_{3}$ and 0.844 at $3.13 \mathrm{MPa} / \mathrm{m}$ in $Y S Z$. These values of $\mathrm{H}_{2}$ fraction exceeded the fraction calculated using the Knudsen equation (0.824). In porous $\mathrm{SiC}$, the 
$\mathrm{H}_{2}$ fraction increased at a lower pressure gradient $(<10 \mathrm{MPa} / \mathrm{m})$ and reached 0.999 at $1.4 \mathrm{MPa} / \mathrm{m}$ of pressure gradient. A similar trend of the dependence of the $\mathrm{H}_{2}$ fraction on the pressure gradient was also observed for the mixed gases with different inlet gas compositions of $20 \mathrm{vol} \% \mathrm{H}_{2}-80 \mathrm{vol} \% \mathrm{CO}_{2}$ and $80 \mathrm{vol} \% \mathrm{H}_{2}-20 \mathrm{vol} \% \mathrm{CO}_{2}$. When $80 \% \mathrm{H}_{2}-20 \% \mathrm{CO}_{2}$ mixed gas was permeated, the $\mathrm{H}_{2}$ fraction was 0.976 at $7.61 \mathrm{MPa} / \mathrm{m}$ in $\mathrm{Al}_{2} \mathrm{O}_{3}, 0.936$ at $3.13 \mathrm{MPa} / \mathrm{m}$ in $\mathrm{YSZ}$, and 0.987 at $3.06 \mathrm{MPa} / \mathrm{m}$ in $\mathrm{SiC}$, respectively. In the case of $20 \% \mathrm{H}_{2}-80 \% \mathrm{CO}_{2}$ mixed gas, the $\mathrm{H}_{2}$ fraction was 0.972 at $6.88 \mathrm{MPa} / \mathrm{m}$ in $\mathrm{Al}_{2} \mathrm{O}_{3}, 0.504$ at $8.04 \mathrm{MPa} / \mathrm{m}$ in YSZ and 0.999 at $3.40 \mathrm{MPa} / \mathrm{m}$ in $\mathrm{SiC}$, respectively. The aforementioned high fraction of $\mathrm{H}_{2}$ gas was closely related to the difference in the critical pressure gradient values for $\mathrm{H}_{2}$ and $\mathrm{CO}_{2}$ single gases, the inlet mixed gas composition, and the gas flow mechanism of the mixed gas. A gas flow of $\mathrm{CO}_{2}$ molecules with a small Knudsen number and the collision between $\mathrm{H}_{2}$ and $\mathrm{CO}_{2}$ molecules control the gas flow mechanism (Poiseuille flow) of the mixed gas. The calculated $\mathrm{H}_{2}$ fraction derived from the modified Poiseuille equations of $\mathrm{H}_{2}$ and $\mathrm{CO}_{2}$ gases explained well the measured $\mathrm{H}_{2}$ fraction as a function of pressure gradient of the mixed gas in $\mathrm{Al}_{2} \mathrm{O}_{3}$ and $\mathrm{SiC}$ porous ceramics. In the present experimental conditions, moisture in atmosphere adsorbed easily on the porous ceramics and affected the critical pressure gradient, leading to the increased selectivity of $\mathrm{H}_{2}$ gas.

Acknowledgments: This work was financially supported by the Budget from Kagoshima University in 2015 and 2016.

Author Contributions: Yoshihiro Hirata conceived and designed the experiments; Hikari Imada and Hikaru Maeda performed the experiments and contributed to the reagents/materials/analysis tools; Taro Shimonosono and Yoshihiro Hirata analyzed the data and proposed the separation model; Taro Shimonosono and Yoshihiro Hirata wrote the paper.

Conflicts of Interest: The authors declare no conflict of interest.

\section{References}

1. David, O.C.; Gorri, D.; Urtiaga, A.; Ortiz, I. Mixed gas separation study for the hydrogen recovery from $\mathrm{H}_{2} / \mathrm{CO} / \mathrm{N}_{2} / \mathrm{CO}_{2}$ post combustion mixtures using a Matrimid membrane. J. Membr. Sci. 2011, 378, 359-368. [CrossRef]

2. Guzmán-Lucero, D.; Palomeque-Santiago, J.F.; Camacho-Zúñiga, C.; Ruiz-Treviño, F.A.; Guzmán, J.; Galicia-Aguilar, A.; Aguilar-Lugo, C. Gas permeation properties of soluble aromatic polyimides based on 4-fluoro-4,4'-diaminotriphenylmethane. Materials 2015, 8, 1951-1965. [CrossRef]

3. Wang, N.; Mundstock, A.; Liu, Y.; Huang, A.; Caro, J. Amine-modified Mg-MOF-74/CPO-27-Mg membrane with enhanced $\mathrm{H}_{2} / \mathrm{CO}_{2}$ separation. Chem. Eng. Sci. 2015, 124, 27-36. [CrossRef]

4. Friebe, S.; Mundstock, A.; Unruh, D.; Renz, F.; Caro, J. $\mathrm{NH}_{2}-\mathrm{MIL}-125$ as membrane for carbon dioxide sequestration: Thin supported MOF layers contra Mixed-Matrix-Membranes. J. Membr. Sci. 2016, 516, 185-193. [CrossRef]

5. Lewis, A.E.; Kershner, D.C.; Paglieri, S.N.; Slepicka, M.J.; Way, J.D. Pd-Pt/YSZ composite membranes for hydrogen separation from synthetic water-gas shift streams. J. Membr. Sci. 2013, 437, 257-264. [CrossRef]

6. De Vos, R.M.; Verweij, H. High-selectivity, high-flux silica membranes for gas separation. Science 1998, 279, 1710-1711. [CrossRef] [PubMed]

7. Basile, A.; Gallucci, F.; Tosti, S. Synthesis, characterisation, and application of palladium membranes. Membr. Sci. Technol. 2008, 13, 255-323.

8. Nayebossadri, S.; Fletcher, S.; Speight, J.D.; Book, D. Hydrogen permeation through porous stainless steel for palladium-based composite porous membranes. J. Membr. Sci. 2016, 515, 22-28. [CrossRef]

9. Kroke, E.; Li, Y.-L.; Konetschny, C.; Lecomte, E.; Fasel, C.; Riedel, R. Silazane derived ceramics and related materials. Mater. Sci. Eng. R 2000, 26, 97-199. [CrossRef]

10. Konegger, T.; Tsai, C.-C.; Peterlik, H.; Creager, S.E.; Bordia, R.K. Asymmetric polysilazane-derived ceramic structures with multiscalar porosity for membrane applications. Microporous Mesoporous Mater. 2016, 232, 196-204. [CrossRef] 
11. Bazarjani, M.S.; Kleebe, H.-J.; Müller, M.M.; Fasel, C.; Baghaie Yazdi, M.; Gurlo, A.; Riedel, R. Nanoporous silicon oxycarbonitride ceramics derived from polysilazanes in situ modified with nickel nanoparticles. Chem. Mater. 2011, 23, 4112-4123. [CrossRef]

12. Sato, H. Chemical Handbook, Basic Region II; Maruzen Co.: Tokyo, Japan, 1984; pp. II38-II39.

13. Maxwell, J.C. Illustrations of the dynamical theory of gases. Philos. Mag. 1860, 19, 19-32.

14. Isobe, T.; Shimizu, M.; Matsushita, S.; Nakajima, A. Preparation and gas permeability of the surface-modified porous $\mathrm{Al}_{2} \mathrm{O}_{3}$ ceramic filter for $\mathrm{CO}_{2}$ gas separation. J. Asian Ceram. Soc. 2013, 1, 65-70. [CrossRef]

15. Takahashi, T.; Tanimoto, R.; Isobe, T.; Matsushita, S.; Nakajima, A. Surface modification of porous alumina filters for $\mathrm{CO}_{2}$ separation using silane coupling agents. J. Membr. Sci. 2016, 497, 216-220. [CrossRef]

16. Shirasaka, H.; Shimonosono, T.; Hirata, Y.; Sameshima, S. Analysis of gas permeability of porous alumina powder compacts. J. Asian Ceram. Soc. 2013, 1, 368-373. [CrossRef]

17. Maeda, H.; Hirata, Y.; Sameshima, S.; Shimonosono, T. Analysis of gas permeability for liquid phase-sintered porous SiC compact. J. Porous Med. 2014, 17, 705-713. [CrossRef]

18. Abrams, H. Grain size measurement by the intercept method. Metallography 1971, 4, 59-78. [CrossRef]

19. Hensler, J.H. The relation between grain section and grain size. J. Inst. Met. 1968, 96, 190-192.

(C) 2016 by the authors; licensee MDPI, Basel, Switzerland. This article is an open access article distributed under the terms and conditions of the Creative Commons Attribution (CC-BY) license (http://creativecommons.org/licenses/by/4.0/). 